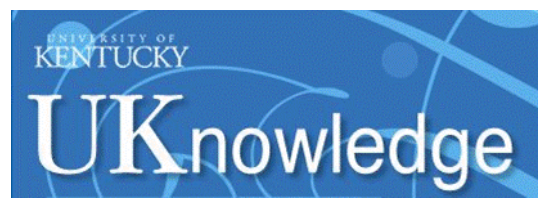

University of Kentucky

UKnowledge

3-31-2017

\title{
Reactivity of Ketyl and Acetyl Radicals from Direct Solar Actinic Photolysis of Aqueous Pyruvic Acid
}

\author{
Alexis J. Eugene \\ University of Kentucky, alexis.eugene@uky.edu \\ Marcelo I. Guzman \\ University of Kentucky, marcelo.guzman@uky.edu
}

Follow this and additional works at: https://uknowledge.uky.edu/chemistry_facpub

Part of the Analytical Chemistry Commons, Atmospheric Sciences Commons, Biochemistry

Commons, Environmental Chemistry Commons, Food Chemistry Commons, Laboratory and Basic

Science Research Commons, Organic Chemistry Commons, and the Physical Chemistry Commons

Right click to open a feedback form in a new tab to let us know how this document benefits you.

\section{Repository Citation}

Eugene, Alexis J. and Guzman, Marcelo I., "Reactivity of Ketyl and Acetyl Radicals from Direct Solar Actinic Photolysis of Aqueous Pyruvic Acid" (2017). Chemistry Faculty Publications. 78.

https://uknowledge.uky.edu/chemistry_facpub/78

This Article is brought to you for free and open access by the Chemistry at UKnowledge. It has been accepted for inclusion in Chemistry Faculty Publications by an authorized administrator of UKnowledge. For more information, please contact UKnowledge@lsv.uky.edu. 


\section{Reactivity of Ketyl and Acetyl Radicals from Direct Solar Actinic Photolysis of Aqueous Pyruvic Acid}

\section{Digital Object Identifier (DOI)}

https://doi.org/10.1021/acs.jpca.6b11916

\section{Notes/Citation Information}

Published in The Journal of Physical Chemistry A, v. 121, no. 15, p. 2924-2935.

Copyright @ 2017 American Chemical Society

ACS AuthorChoice - This is an open access article published under an ACS AuthorChoice License, which permits copying and redistribution of the article or any adaptations for non-commercial purposes. 


\title{
Reactivity of Ketyl and Acetyl Radicals from Direct Solar Actinic Photolysis of Aqueous Pyruvic Acid
}

\author{
Alexis J. Eugene and Marcelo I. Guzman*(i) \\ Department of Chemistry, University of Kentucky, Lexington, Kentucky 40506, United States \\ Supporting Information
}

\begin{abstract}
The variable composition of secondary organic aerosols (SOA) contributes to the large uncertainty for predicting radiative forcing. A better understanding of the reaction mechanisms leading to aerosol formation such as for the photochemical reaction of aqueous pyruvic acid (PA) at $\lambda \geq 305 \mathrm{~nm}$ can contribute to constrain these uncertainties. Herein, the photochemistry of aqueous PA $(5-300 \mathrm{mM})$ continuously sparged with air is re-examined in the laboratory under comparable irradiance at $38^{\circ} \mathrm{N}$ at noon on a summer day. Several analytical methods are employed to monitor the time series of the reaction, including (1) the derivatization of carbonyl $(\mathrm{C}=\mathrm{O})$ functional groups with 2,4-dinitrophenylhydrazine (DNPH), (2) the separation of photoproducts by ultrahigh pressure liquid chromatography (UHPLC) and ion chromatography (IC) coupled to mass spectrometry (MS), (3) high resolution MS, (4) the assignment of ${ }^{1} \mathrm{H}$ NMR and ${ }^{13} \mathrm{C}$ gCOSY spectroscopic features, and (5) quantitative ${ }^{1} \mathrm{H}$ NMR. The primary

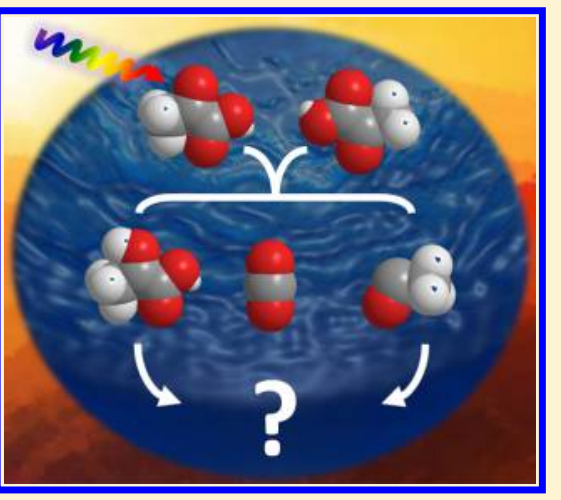
photoproducts are 2,3-dimethyltartaric acid and unstable 2-(1-carboxy-1-hydroxyethoxy)-2-methyl-3-oxobutanoic acid, a polyfunctional $\beta$-ketocarboxylic acid with eight carbons $\left(\mathrm{C}_{8}\right)$ that quickly decarboxylates into 2-hydroxy-2-((3-oxobutan-2yl)oxy)propanoic acid. Kinetic isotope effect studies performed for the first time for this system reveal the existence of tunneling during the initial loss of PA. Thus, the KIEs support a mechanism initiated by photoinduced proton coupled electron transfer $(\mathrm{PCET})$. Measured reaction rates at variable initial $[\mathrm{PA}]_{0}$ were used to calculate the sum of the quantum yields for the products, which displays a hyperbolic dependence: $\sum \Phi_{\text {product }}=1.99[\mathrm{PA}]_{0} /\left(113.2+[\mathrm{PA}]_{0}\right)$. The fast photochemical loss of aqueous PA with an estimated lifetime of $21.7 \mathrm{~min}$ is interpreted as a significant atmospheric sink for this species. The complexity of these aqueous phase pathways indicates that the solar photochemistry of an abundant $\alpha$-ketocarboxylic acid can activate chemical processes for SOA formation.
\end{abstract}

\section{INTRODUCTION}

Recently, the contribution of the aqueous phase photochemistry of $\alpha$-ketocarboxylic acids, e.g., glyoxylic acid and pyruvic acid (PA), to the formation of secondary organic aerosols (SOA) has been recognized as important. ${ }^{1-6}$ The oxidation of aromatic compounds from combustion ${ }^{7}$ and biomass burning emissions ${ }^{8}$ produces a variety of lowmolecular-weight organic acids, including PA. ${ }^{9,10}$ Similarly, the photooxidation of isoprene ${ }^{11}$ results in the production of methacrolein in the gas phase, ${ }^{12,13}$ which is further oxidized to form water-soluble methylglyoxal (Henry's law constant $K_{\mathrm{H}}=$ $\left.3.71 \times 10^{3} \mathrm{M} \mathrm{atm}^{-1}\right) \cdot{ }^{14,15}$ After methylglyoxal partitions to condensed phases, it is quickly hydrated $\left(K_{\text {hyd }}=2.7 \times 10^{3}\right){ }^{16}$ and subsequently undergoes efficient oxidation to PA with a $92 \%$ yield. ${ }^{17,18}$ Furthermore, out of 92 compounds studied, the direct photolysis of PA is predicted as the most favorable one to outcompete oxidation by $\mathrm{HO}^{\bullet}$ in atmospheric waters. ${ }^{19}$

Aqueous PA $\left(K_{\text {hyd }}=2.10\right)^{20}$ at room temperature is available as $32 \%$ carbonyl $(\mathrm{C}=\mathrm{O})$ form in equilibrium with $68 \%$ of its hydrate, 2,2-dihydroxypropanoic acid (DHPA). Thus, the strong $\mathrm{n} \rightarrow \pi^{*}$ absorption of PA at $\lambda=321( \pm 20) \mathrm{nm}$ can induce sunlight-driven photochemistry, as shown in Scheme $1 .{ }^{21}$
Upon photon absorption in water, the produced singlet excited state can undergo intersystem crossing, forming a triplet excited state with a quantum yield $\Phi_{\mathrm{T}}=0.22$ (for $0.10 \mathrm{M} \mathrm{PA}$ ), and a lifetime ${ }^{3} \tau_{\text {pyruvic acid }}=74 \mathrm{ns.}^{22}$ The unequivocal interpretation of (1) electron paramagnetic resonance (EPR) spectra of irradiated aqueous PA glasses ${ }^{23}$ together with (2) a kinetic model and product analysis ${ }^{2}$ and (3) the use of TEMPO radical scavenger under a broad temperature range ${ }^{21,23}$ demonstrated that the dominant condensed phase photochemistry mechanism (for photodecarboxylation $\left(\Phi_{-\mathrm{CO}_{2}}=0.78\right.$ at $293 \mathrm{~K})^{21}$ is promoted by proton-coupled electron transfer (PCET) between a triplet excited state pyruvic acid $\left(\mathrm{PA}^{*}\right)$ and a ground state PA molecule. ${ }^{2,21-24}$ The resulting ketyl $\left(\mathrm{K}^{\bullet}\right)$ and acetyl $\left(\mathrm{Y}^{\bullet}\right)$ radicals are key in this process. ${ }^{2}$ In the presence of air, electron transfer from $\mathrm{PA}^{*}$ to $\mathrm{O}_{2}$ may occur, providing a source of superoxide and another pathway to form $\mathrm{Y}^{\bullet}{ }^{25}$

The proposed reaction mechanism (Scheme 1) explains the large evolution of primary and secondary $\mathrm{CO}_{2}(\mathrm{~g})$ during and after irradiation, as well as the low-molecular-weight polyfunc-

Received: November 26, 2016

Revised: March 13, 2017

Published: March 31, 2017 
Scheme 1. Reaction Mechanism of Sunlight Irradiated Aqueous Pyruvic Acid (PA) ${ }^{a}$

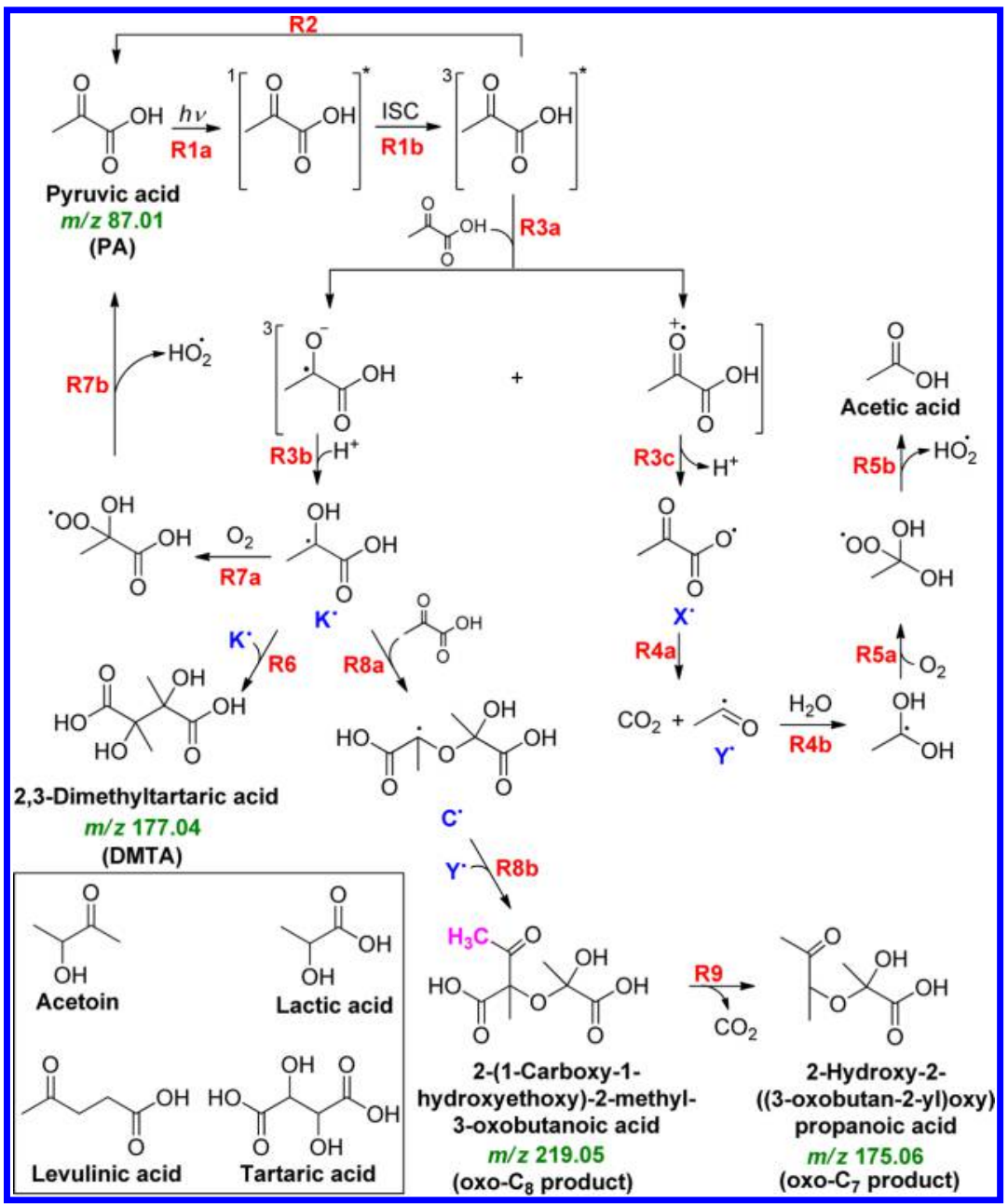

${ }^{a}$ Radical intermediates $\mathrm{C}^{\bullet}, \mathrm{K}^{\bullet}, \mathrm{X}^{\bullet}$, and $\mathrm{Y}^{\bullet}$ labeled in blue font and products observed labeled in bold black font. ${ }^{2,21}$ The inset shows the compounds that were previously proposed but which we did not observe (acetoin and lactic acid) and proxy standards used for quantification (levulinic and tartaric acids).

tional major photoproducts in water and ice: 2,3-dimethyltartaric acid (DMTA) and 2-(3-oxobutan-2-yloxy)-2-hydroxypropanoic acid (the oxo- $\mathrm{C}_{7}$ product). ${ }^{2,21}$ Conversely, the possibility that other minor photoproducts, particularly acetoin, acetic, and lactic acids, could be generated has recently been reinstated ${ }^{3,26}$ based on an alternative mechanism supported by twodimensional nuclear magnetic resonance (NMR) spectroscopy for a mixture of products, ${ }^{26}$ via an $\alpha$-acetolactic acid intermediate. Remarkably, this alternative reaction mechanism proceeds through the formation of $\mathrm{K}^{\bullet}$ and $\mathrm{Y}^{\bullet}$ radicals too, ${ }^{26}$ resulting in the same major photoproducts ${ }^{27}$ observed before. $^{2,21}$ However, acetoin was previously confirmed to be an artifact resulting from the decomposition of the thermolabile oxo- $\mathrm{C}_{7}$ product at the high temperatures of gas chromatography analysis ${ }^{2}$ performed by Leermakers and Vesley. ${ }^{28}$ Moreover, we have recently reapproached the determination of acetoin as a photoproduct in the gas and liquid phase and quantitatively determined that its upper limit concentration would not exceed $0.006 \%$ of the total pyruvic acid converted. ${ }^{29}$ Additionally, arguments supporting acetoin production from an $\alpha$-acetolactic acid intermediate ${ }^{26,29}$ can be discarded based on previous studies, which are summarized below. ${ }^{2,21}$ Continuous post-photolysis $\mathrm{CO}_{2}$ evolution well below $4{ }^{\circ} \mathrm{C}$, the minimum temperature for $\alpha$-acetolactic acid decarboxylation, ${ }^{30}$ indicated that a different intermediate was the dominant primary photoproduct that undergoes $\beta$-ketocarboxylic acid decarboxylation. ${ }^{2,21}$ These decarboxylation tests were carefully performed by quickly starting with stable solutions of $\alpha$-acetolactic acid kept at $1{ }^{\circ} \mathrm{C}$, in the sealed photochemical reactor, which were acidified and rapidly thermalized to the desired final temperature of experiments, covering the range from -20 to 20 ${ }^{\circ} \mathrm{C} .{ }^{2,21}$ Past experiments below $4{ }^{\circ} \mathrm{C}$ assured that $\alpha$-acetolactic acid was available unaltered during the reaction, ${ }^{21}$ discarding any concern raised about the availability of thermally labile $\alpha$ acetolactic acid ${ }^{27}$ in previous work.

In order to assess if results from different analytical techniques could support or contradict each other, affecting the interpretation of the photochemical mechanism, ${ }^{27,29}$ herein we reexamine the direct photolysis of aqueous PA under an environmentally relevant range of concentrations. Low levels of acetic acid are produced in the presence of air and quantified, while the photochemical production of acetoin and lactic acid is shown not to occur by a combination of NMR spectroscopy, liquid chromatography, and mass spectrometry (MS). The work identifies for the first time 2-(1-carboxy-1-hydroxyethoxy)-2-methyl-3-oxobutanoic acid (oxo- $\mathrm{C}_{8}$ product) as the missing intermediate and precursor to the oxo- $\mathrm{C}_{7}$ product after $\beta$-ketocarboxylic acid decarboxylation. The identification of this 
intermediate strongly supports a relevant bimolecular mechanism for the photochemistry of aqueous PA.,21-25

\section{EXPERIMENTAL SECTION}

Preparation of Experiments. All experiments were performed in duplicate. The concentration of PA was chosen based on its reported molar ratio to sulfate ranging from $2.5 \times$ $10^{-4}$ to $10.7 \times 10^{-3}$ in urban aerosols. ${ }^{31-33}$ For the range of relative humidity $50-90 \%,{ }^{34}$ water uptake by acidic aerosol is dominated by the deliquescence of ammonium bisulfate, which dictates that liquid particles have a ratio of $\sim 0.6 \mathrm{~g} \mathrm{H}_{2} \mathrm{O} / 1 \mathrm{~g}$ sulfate. ${ }^{35,36}$ This reasoning indicates that urban aerosols can be highly acidic and contain 5-250 mM PA. Undissociated PA is a remarkably photoreactive molecule in contrast to its conjugate base. $^{28}$ Thus, fresh solutions of ca. 5, 25, 50, 75, and $100 \mathrm{mM}$ pyruvic acid (Sigma-Aldrich, 98.5\%, distilled under vacuum) in ultrapure water (18.2 $\mathrm{M} \Omega \mathrm{cm}^{-1}$, Elga Purelab Flex, Veolia) were used in typical experiments. The $\mathrm{pH}$ of the solutions was adjusted to 1.0 with hydrochloric acid (EMD, 38\%) as monitored with a calibrated $\mathrm{pH}$-meter (Thermo Scientific), to provide a fraction of undissociated $\mathrm{PA}\left(\mathrm{p} K_{\mathrm{a}}=2.4 \text { at } 298 \mathrm{~K}\right)^{37}>$ 0.96. Alternatively, selected experiments used fully ${ }^{13} \mathrm{C}$ labeled sodium pyruvate (Cambridge Isotope Laboratories, 99.7\%, 99.3\% isotope enrichment) acidified to $\mathrm{pH}=1.0$ and subjected to the same experimental conditions for comparison to the unlabeled isotopologue. The kinetic isotope effect (KIE) was studied for PA solutions in $\mathrm{D}_{2} \mathrm{O}$ (Cambridge Isotope Laboratories, 99.9\%). Deuterated hydrochloric acid (DCl, Cambridge Isotope Laboratories, $35.6 \%$ in $\mathrm{D}_{2} \mathrm{O}, 99.8 \%$ isotope enrichment) was used to adjust to $\mathrm{pD}=1.0$ ( $\mathrm{pH}$-meter reading of 0.6$)^{38}$ during KIE experiments for comparison to the experiment in $\mathrm{H}_{2} \mathrm{O}$. Solutions were sparged at $30 \mathrm{~mL} \mathrm{~min}{ }^{-1}$ with air (Scott-Gross, UHP) for at least 30 min before starting irradiation of aliquots in $5 \mathrm{~mm}$ borosilicate NMR tubes (Wilmad) of optical path length $l=0.424 \mathrm{~cm}$. Similarly, controls were performed employing $1 \mathrm{~atm} \mathrm{~N}_{2}(\mathrm{~g})$ (Scott-Gross, UHP) and 1 atm $\mathrm{O}_{2}(\mathrm{~g})$ (Scott-Gross, UHP) instead of air. Additional experiments under continuous sparging with 1 atm air or controls under 1 atm $\mathrm{N}_{2}(\mathrm{~g})$ or 1 atm $\mathrm{O}_{2}(\mathrm{~g})$ were also performed in a photoreactor $(220 \mathrm{~mL}$ capacity) as described in our previous work. ${ }^{5}$

Photochemical Conditions. For irradiation, a $1 \mathrm{~kW}$ highpressure $\mathrm{Xe}-\mathrm{Hg}$ lamp was used ${ }^{5}$ in combination with (1) a water filter to remove infrared radiation, and (2) a cutoff filter at wavelength $\lambda \geq 305 \mathrm{~nm}$ to provide near UV and visible radiation. Neutral density filters were employed to measure an attenuated $\left(10.64 \%\right.$ of the total) incident photon rate, $I_{0}=1.14$ $( \pm 0.05) \times 10^{-5}$ Einstein $\mathrm{L}^{-1} \mathrm{~s}^{-1}$, by chemical actinometry with phenylglyoxylic acid. ${ }^{39}$ The irradiance utilized is comparable to that of Earth at $38^{\circ} \mathrm{N}$ at noon on a summer day. Reported quantum yields were obtained under light attenuation from initial reaction rates and the calculated absorbed photon rates for variable [PA].

Analysis of Products. Analyses report the average value from two independent experiments with its corresponding standard deviation. All plots include error bars even though they could be smaller than the symbols shown. For product analysis in water, fresh samples were immediately analyzed to avoid further thermal processing. IC-MS, UHPLC-MS, high resolution MS (HRMS), and both ${ }^{1} \mathrm{H}$ and ${ }^{13} \mathrm{C}$ NMR were employed. The gas phase product analysis by Fourier transform infrared spectroscopy (FTIR) was described previously and the detailed peak assignment is available in Table S1 (Supporting
Information). ${ }^{5}$ The percentage of PA lost during the reaction is referred to by the term conversion. In order to avoid secondary processes from generated photoproducts that could lead to identification of incorrect reaction mechanisms, the photochemical reaction is generally studied for an arbitrary conversion $<30 \%$, unless noted otherwise.

IC-Conductivity-MS Analysis. Samples were analyzed by IC-MS using a Dionex ICS-2000 ion chromatograph (IonPack AS11-HC, $2 \mathrm{~mm}$ column) equipped with a conductivity detector and an electrospray ionization (ESI) MS (Thermo Scientific MSQ Plus). ${ }^{40}$ Anions were detected at exact mass-tocharge ratios $(\mathrm{m} / \mathrm{z})$ corresponding to the loss of a proton from the molecular weight of the parent molecule. Importantly, these chromatographic analyses indicated that PA needed to be distilled initially when received and periodically thereafter to remove traces of acetic $(m / z 59.01)$, parapyruvic $(m / z 175.02)$, and zymonic acid $(m / z$ 157.01) impurities (Figure $S 1$, Supporting Information), which form slowly over time even when stored in the dark below $8{ }^{\circ} \mathrm{C}$ and could interfere with analysis of the chemical mechanism. It is worth noting that in samples of pyruvic acid that have not been distilled, our IC-MS analysis allows for a separation of more than $10 \mathrm{~min}$ between peaks for the photoproduct oxo- $\mathrm{C}_{7}$ and the impurity parapyruvic acid, both with $m / z 175$.

UHPLC-UV-MS Analysis. For carbonyl analysis, samples were derivatized with 2,4-dinitrophenylhydrazine (DNPH, Sigma-Aldrich, 99.6\%) and separated on a Thermo Scientific Accela 1250 UHPLC equipped with tandem photodiode array (PDA) and ESI-MS (negative mode) detectors. The separation was adapted from previous work ${ }^{5}$ using the same $\mathrm{C} 18$ column (hypersil gold, $1.9 \mu \mathrm{m}, 50 \times 2.1 \mathrm{~mm}$, Thermo Scientific) but using a water/methanol gradient for elution instead of water/ acetonitrile. Additionally, the analysis of samples not treated with DNPH was performed (Figure S2) as described in the Supporting Information.

HRMS. Samples were analyzed in a quadrupole Orbitrap ( $Q$ Exactive, Thermo Scientific) mass spectrometer operating in ESI negative mode with an internal lock mass for $\mathrm{m} / \mathrm{z}$ calibration. The following parameters were applied: sheath gas flow $10 \mathrm{~L} \mathrm{~min}^{-1}$, capillary temperature of $320^{\circ} \mathrm{C}$, and a heater temperature of $30^{\circ} \mathrm{C}$. The AGC target was set to $3 \times 10^{6}$ and the maximum injection time to $250 \mathrm{~ms}$. Three Microscans were averaged per scan for high resolution measurements at 140000 at $m / z 255.2322$. The spray voltage was operated at $3.2 \mathrm{kV}$. The S-lens RF level was set to 50.0 and the scan range to $\mathrm{m} / \mathrm{z}$ 50-400. Samples were diluted 44-times in 1:1 acetonitrile:water for direct infusion $\left(5 \mu \mathrm{L} \mathrm{min}{ }^{-1}\right)$ into an ESI source.

Quantitative Analysis. Chromatographic quantification of products employed commercially available standards to prepare calibration curves. Levulinic (Sigma-Aldrich, 98.6\%) and L(+)-tartaric (Sigma-Aldrich, 99.8\%) acids were used as proxies for candidate products that were not available commercially. Chromatographic relative response factors for the proxy molecules and the products were determined by quantitative NMR (qNMR) following literature procedures, ${ }^{41}$ for accurate quantification by IC and UHPLC.

NMR Spectroscopy. Samples for NMR were spiked with $10 \% \mathrm{v} / \mathrm{v} \mathrm{D}_{2} \mathrm{O}$ containing 4,4-dimethyl-4-silapentane-1-sulfonic acid (DSS, Aldrich, 97\%) and gadolinium(III) chloride hexahydrate (Aldrich, 99.999\%). ${ }^{5}{ }^{1} \mathrm{H}$ NMR spectra were recorded at $400 \mathrm{MHz}$ (Varian 400-MR), unless noted otherwise, utilizing a WET $1 \mathrm{D}$ water suppression pulse sequence. Acetic acid (Acros, 100\%) and acetoin (Aldrich, 
99.1\%) were quantified in ${ }^{1} \mathrm{H}$ NMR samples using a four point standard addition. The method is capable of providing highly accurate quantifications down to 3-times the lower concentration spiked, ${ }^{42}$ which covered the range 169-732 $\mu \mathrm{M}\left(r^{2}=\right.$ $0.986)$ and 64-1350 $\mu \mathrm{M}\left(r^{2}=0.999\right)$ for acetic acid and acetoin, respectively. More importantly, these spikes were also used for qualitative comparison of spectral features along with a spike of lactic acid (Sigma-Aldrich, $88.6 \%$ in water). ${ }^{1} \mathrm{H}$ NMR predictions were performed in NMRpredict (Modgraph Consultants Ltd.) integrated into MestReNova software, using the BEST algorithm. ${ }^{43}$ The algorithm uses a combination of NMR tables and parametrized functional groups to calculate probable chemical shifts. For experiments with ${ }^{13} \mathrm{C}$ labeled PA, proton decoupled ${ }^{13} \mathrm{C}$ gradient correlation spectroscopy (gCOSY NMR) ${ }^{44}$ was recorded at $150 \mathrm{MHz}$ (Varian Inova AS600). The latter instrument was also employed for the assignment of ${ }^{1} \mathrm{H}$ NMR spectra at $600 \mathrm{MHz}$.

\section{RESULTS AND DISCUSSION}

IC-MS Analysis. Figure 1A shows the IC chromatograms for the time series of an experiment with $113.7 \mathrm{mM}$ PA

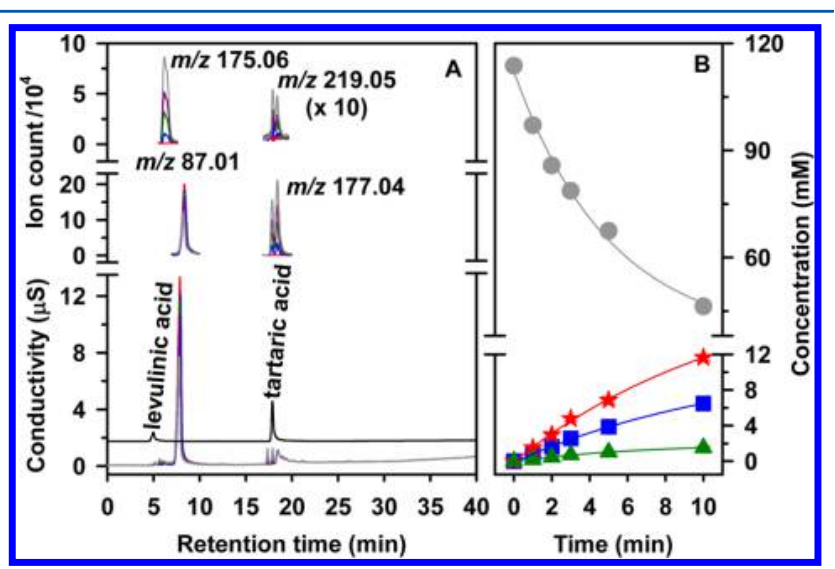

Figure 1. (A) IC total conductivity and $\operatorname{ESI}(-) / \mathrm{MS}$ extracted ion chromatograms (EIC) of $113.7 \mathrm{mM}$ pyruvic acid (PA) photolyzed at $\lambda$ $\geq 305 \mathrm{~nm}$, without neutral density filters, for (red) 0; (blue) 1 ; (green) 3; (purple) 5; and (gray) $10 \mathrm{~min}$. Levulinic and tartaric acid standards are displayed in a black trace for reference. (B) Time series for (gray circle) PA loss at $m / z$ 87.01, and formation of (red star) the oxo- $C_{7}$ product at $m / z 175.06$, (blue square), DMTA at $m / z$ 177.04, and (green triangle) the oxo- $\mathrm{C}_{8}$ product at $\mathrm{m} / z 219.05$.

irradiated at $\lambda \geq 305 \mathrm{~nm}$. The extracted ion chromatograms (EIC) reveal several anionic species with four different molecular weights eluting at (1) $6.36 \mathrm{~min}(\mathrm{~m} / z$ 175.06), (2) $7.74 \mathrm{~min}(\mathrm{~m} / z$ 87.01), (3) $17.89 \mathrm{~min}(\mathrm{~m} / z$ 219.05), (4) 18.39 $\min (\mathrm{m} / z 219.05)$, (5) $17.90 \mathrm{~min}(\mathrm{~m} / z$ 177.04), and (6) 18.45 $\min (m / z 177.04)$. While some of these species coelute, generating a superimposed conductivity peak, the MS detector can deconvolute these carboxylic acid products. Standard solutions of PA are confirmed to elute at $7.74 \mathrm{~min}(\mathrm{~m} / z$ 87.01); all other chromatographic peaks observed correspond to reaction products. The black trace in Figure 1A displays a chromatogram for a mixture of levulinic and tartaric acids (see structures included in the box in Scheme 1) eluting at 4.98 and $17.87 \mathrm{~min}$, respectively. The earlier retention time $(5-7 \mathrm{~min})$ of simple oxo-carboxylic acids such as levulinic acid and PA (with only one $-\mathrm{COOH}$ group) than tartaric acid (a dicarboxylic acid) (18 $\mathrm{min})$ indicates that mono- and dicarboxylic acids are well separated in the chromatographic column. From this information, it can be concluded that the species eluting at $6.36 \mathrm{~min}(\mathrm{~m} / z 175.06)$ is a monocarboxylic acid with neutral mass of 176.17 atomic mass units (amu). In addition, both species eluting later with $\mathrm{m} / z 219.05$ and 177.04 are dicarboxylic acids with neutral masses of 220.18 and 178.14 amu, respectively.

Despite the power of the MS to resolve both species at $\mathrm{m} / \mathrm{z}$ 177.04 and 219.05 coeluting in the IC chromatogram, a better time separation was also accomplished by direct UHPLC-MS analysis (Figure S2, Supporting Information).

Previous work identified two carboxylic acid major photoproducts with molecular weights of 176.17 and $178.14 \mathrm{amu}$ in the $\lambda=320( \pm 10) \mathrm{nm}$ photolysis of PA. ${ }^{2}$ Thus, present results agree with previous findings, as depicted in Scheme 1. The dicarboxylic acid with a mass of 178.14 amu species is identified as DMTA, and the monocarboxylic acid with a mass of 176.17 amu is the oxo- $C_{7}$ product (Scheme 1). A structure for a $\beta$ ketocarboxylic acid intermediate with a neutral mass of 220.18 amu was provided, ${ }^{2,21}$ and corresponds to the oxo- $\mathrm{C}_{8}$ product eluting at 17.89 and $18.39 \mathrm{~min}$. The clear identification of the oxo- $\mathrm{C}_{8}$ product in Figure $1 \mathrm{~A}$, which is the intermediate undergoing thermal $\beta$-ketocarboxylic acid decarboxylation into the oxo- $\mathrm{C}_{7}$ product, $^{21}$ strongly supports the mechanism proposed in Scheme 1.

The oxo- $\mathrm{C}_{8}$ product and DMTA display two distinct chromatographic peaks in both the conductivity and the EIC chromatograms, which show the presence of at least two stereoisomers of each species. Given the radical mechanism proposed in Scheme 1 and the presence of two stereocenters in each product, four stereoisomers of each product should theoretically be formed with equal probability. DMTA is a meso compound, reducing the number of distinct stereoisomers to only three. Thus, one chromatographic peak at $17.07 \mathrm{~min}$ is proposed to arise from meso-2,3-dimethyltartaric acid and the other at $17.61 \mathrm{~min}$ to inseparable $(R, R)$ and $(S, S)$ enantiomers. Close inspection of the broad peak for the oxo- $C_{7}$ product indicates a small shoulder at the top left-hand side, suggesting that two coeluting peaks from diastereomers are possible.

Figure 1B displays the time series of product formation and the loss of PA extracted from the data in Figure 1A. The firstorder decay of PA fits an exponential function with a coefficient of correlation $r^{2}=0.994$, and rate constant, $k_{\text {-PA }}=3.28 \times 10^{-3}$ $\mathrm{s}^{-1}$. Similarly, the concentrations of DMTA and the oxo- $\mathrm{C}_{7}$ and oxo- $\mathrm{C}_{8}$ products increase exponentially according to the equation

$$
[\text { product }](\mathrm{mM})=[\text { product }]_{\infty}\left(1-\mathrm{e}^{-k_{\mathrm{f}} t}\right)
$$

where the time $t$ is given in min, the [product $]_{\infty}$ is a constant (Table 1) that represents the asymptotic upper limit that would be reached as $t \rightarrow \infty$, and $k_{\mathrm{f}}$ is the formation rate constant. All nonlinear fittings in Figure 1B have $r^{2} \geq 0.995$. Although the

Table 1. Exponential Growth Parameters for Products in Figure 1 and $\mathrm{KIE}$ in $\mathrm{D}_{2} \mathrm{O}$

\begin{tabular}{lccc}
\multicolumn{1}{c}{ product } & $\begin{array}{c}\text { [product }]_{\infty} \\
(\mathrm{mM})\end{array}$ & $k_{\mathrm{f}}\left(\mathrm{s}^{-1}\right)$ & $\mathrm{KIE}$ \\
2,3-Dimethyl tartaric acid & 12.79 & $1.18 \times 10^{-3}$ & $5.61 \times 10^{1}$ \\
Oxo-C $_{7}$ & 21.35 & $1.32 \times 10^{-3}$ & $7.23 \times 10^{2}$ \\
Oxo-C $_{8}$ & 2.08 & $2.22 \times 10^{-3}$ & $1.70 \times 10^{3}$
\end{tabular}


precursor oxo- $\mathrm{C}_{8}$ product is unstable, its expected behavior follows the trend for the daughter oxo- $\mathrm{C}_{7}$ species.

Experiments with ${ }^{13} \mathrm{C}$ Labeled PA and KIE in $\mathrm{D}_{2} \mathrm{O}$. Further confirmation of the structure of products was provided by photolyzing ${ }^{13} \mathrm{C}$ labeled PA solutions. Figure $2 \mathrm{~A}$ shows the

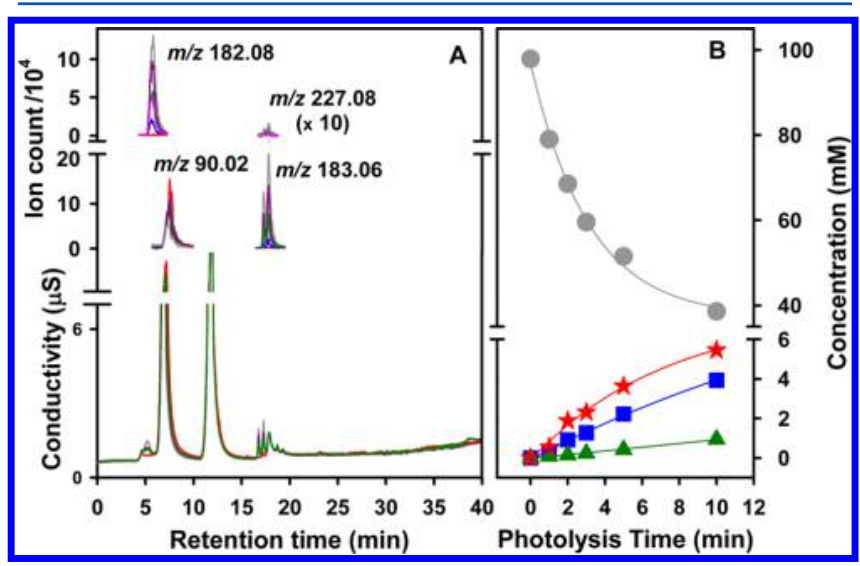

Figure 2. (A) IC total conductivity and ESI(-)/MS EIC of $97.88 \mathrm{mM}$ ${ }^{13} \mathrm{C}$ labeled PA photolyzed for (red) 0; (blue) 1; (pink) 2; (green) 3; (purple) 5; and (gray) $10 \mathrm{~min}$. (B) Time series for (gray circle) PA loss at $\mathrm{m} / z$ 90.02, and formation of (red star) the oxo- $\mathrm{C}_{7}$ product at $\mathrm{m} / z$ 182.08, (blue square), DMTA at $\mathrm{m} / z$ 183.06, and (green triangle) the oxo- $\mathrm{C}_{8}$ product at $\mathrm{m} / z$ 227.08. All other conditions as presented for Figure 1.

total conductivity chromatograms and EIC for the major species observed in this experiment. As expected, the anion for ${ }^{13} \mathrm{C}$ labeled PA is observed at $\mathrm{m} / z 90.02$ (Figure 2A), $3 \mathrm{amu}$ heavier than for unlabeled PA. The $-\mathrm{COOH}$ group for one of the major products of the reaction appears at $\mathrm{m} / \mathrm{z} 182.08$ (Figure 2).

This seven carbon species is 7 amu heavier than the unlabeled oxo- $\mathrm{C}_{7}$ product observed in Figure 1. The other major product in Figure 2A is observed as two peaks with $\mathrm{m} / \mathrm{z}$ 183.06, 6 amu higher than the proposed six carbon structure for DMTA. Finally, the intermediate oxo- $\mathrm{C}_{8}$ product is observed at the predictable $m / z 227.08$ (Figure 2), 8 amu heavier than the unlabeled product in Figure 1.

Figure $2 \mathrm{~B}$ shows the exponential decay of ${ }^{13} \mathrm{C}$ labeled PA and exponential rise analogous to the unlabeled products in Figure 1B. When comparing the data in Figures $2 \mathrm{~B}$ to $1 \mathrm{~B}$, an isotope effect is apparent from the lower [products] in the experiment with ${ }^{13} \mathrm{C}$ labeled PA. Additional experiments (Figure S3, Supporting Information) explored the effect of substituting $\mathrm{H}_{2} \mathrm{O}$ by $\mathrm{D}_{2} \mathrm{O}$ in experiments aimed at determining global KIE. The initial slopes in Figure $1 \mathrm{~B}$ and Figure S3 (Supporting Information) are used to calculate the KIE for product formation displayed in Table 1 . The reported KIE are defined for first order processes by the ratio of initial formation rate constants $k_{\mathrm{f}}$ for experiments in $\mathrm{H}_{2} \mathrm{O}$ and $\mathrm{D}_{2} \mathrm{O}$ at $\mathrm{pH}$ or $\mathrm{pD} 1.0$ under the full photon rate: ${ }^{45}$

$$
\mathrm{KIE}=\frac{k_{\mathrm{f}, \mathrm{H}_{2} \mathrm{O}}}{k_{\mathrm{f}, \mathrm{D}_{2} \mathrm{O}}}
$$

The KIE in eq 2 encompasses all the steps required to form the products, including bond breaking and bond making. ${ }^{45}$ From the viewpoint of pathways undergoing KIE, the reaction for the loss of PA must be considered as going through a transition state en route to producing the radicals $\mathrm{K}^{\bullet}$ and $\mathrm{X}^{\bullet}$. This transition state is stabilized differently by $\mathrm{H}_{2} \mathrm{O}$ and $\mathrm{D}_{2} \mathrm{O}$ leading to a primary KIE. A purely primary KIE $\sim 6.5$ value for ${ }^{1} \mathrm{H} /{ }^{2} \mathrm{H}$ should be expected at $298 \mathrm{~K}$ for homolysis generating two radicals, ${ }^{45}$ such as in the unimolecular Norrish type I cleavage of PA in the gas phase. ${ }^{46}$ However, the initial loss of PA showing a large $\mathrm{KIE}_{-\mathrm{PA}}=9.09$, supports a mechanism involving PCET, which is equivalent to $\mathrm{H}$ atom transfer. ${ }^{2}$ In addition, the large $\mathrm{KIE}_{-\mathrm{PA}}$ disfavors the possibility of a nonlinear transition state as would occur for hydrogen abstraction from the methyl group of PA implied in other mechanisms. ${ }^{3,26}$ This bimolecular process is energetically favorable due to energy released during the decarboxylation of $\mathrm{X}^{\bullet}$. ${ }^{2}$ The large $\mathrm{KIE}_{-\mathrm{PA}}$ should involve tunneling, i.e., as typical for acid-base reactions. In other words, we propose the large $\mathrm{KIE}_{-\mathrm{PA}}$ observed is expected when the acid strengths for ground state PA and the triplet excited state are comparable. Perhaps, if the rate-determining step would have proceeded through an activated complex with bent bonds, ${ }^{26}$ e.g., for a transition state displaying a considerable hybridization change to a $\mathrm{C}_{\mathrm{sp}}{ }^{2}$ centered radical for $\mathrm{H}$ atom abstraction from the terminal methyl group with a $\mathrm{C}_{\mathrm{sp}}{ }^{3}$, a smaller KIE should have been measured. ${ }^{45}$

The dramatically large KIE values for the generation of DMTA and the oxo- $\mathrm{C}_{7}$ product (Table 1 ) reveal tunneling also occurs for the conversion of radical intermediates and ground state PA into the final products. The penetration of the wave function of the precursor species through the barrier for the reaction occurs more commonly for molecules with $\mathrm{H}$ atoms than for the deuterated version. ${ }^{45}$ Tunneling is typically associated with proton transfer or $\mathrm{H}$-transfer or electron transfer, all processes that depend exponentially on the mass of the isotope, and thus decrease when transferring from $\mathrm{H}_{2} \mathrm{O}$ to $\mathrm{D}_{2} \mathrm{O} .{ }^{45}$ Remarkably, the KIE for the generation of the oxo- $\mathrm{C}_{8}$ product (Table 1) should also involve tunneling for the $\beta$ ketocarboxylic acid decarboxylation taking place with intramolecular H-transfer. These KIE for products have larger activation energy differences between the compounds containing ${ }^{1} \mathrm{H}$ and ${ }^{2} \mathrm{H}$ than their differences in zero point energy.

HRMS. High resolution mass spectrometry provided confirmation of the molecular formulas that were proposed above. The full HRMS spectrum of a $100.0 \mathrm{mM}$ pyruvic acid solution photolyzed to $20 \%$ conversion is shown in Figure 3. Both pyruvic acid $(m / z$ 87.0083) and its hydrate (DHPA, $m / z$ 105.0192) were observed by this method.

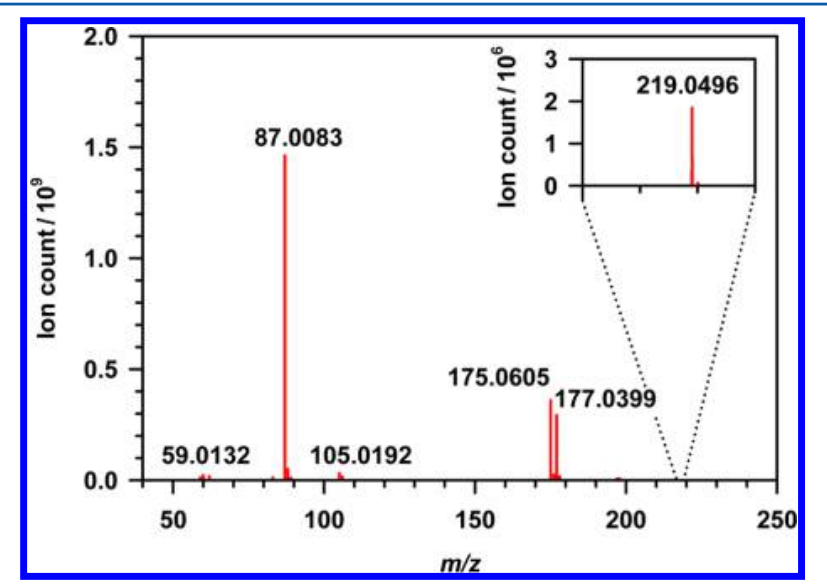

Figure 3. High resolution mass spectrum of $100.0 \mathrm{mM}$ pyruvic acid photolyzed to $20 \%$ conversion with inset showing the oxo- $\mathrm{C}_{8}$ product $(m / z 219.0596)$. 
Table 2 lists the observed and theoretical $\mathrm{m} / z$ values for pyruvic acid and each of the products detected as well as the

Table 2. High Resolution MS Analysis for $100.0 \mathrm{mM}$ PA Photolyzed to a $20 \%$ Conversion

\begin{tabular}{lcccc}
\multicolumn{1}{c}{ species } & $\begin{array}{c}\text { observed } \\
(\mathrm{m} / z)\end{array}$ & $\begin{array}{c}\text { theoretical } \\
(\mathrm{m} / z)\end{array}$ & $\begin{array}{c}\text { mass defect } \\
(\mathrm{ppm})\end{array}$ & $\begin{array}{c}\{\mathrm{M}-\mathrm{H}\}^{-} \\
\text {formula }\end{array}$ \\
$\mathrm{PA}$ & 87.0083 & 87.0088 & 5.74 & $\mathrm{C}_{3} \mathrm{H}_{3} \mathrm{O}_{3}{ }^{-}$ \\
$\mathrm{DHPA}$ & 105.0192 & 105.0193 & 0.95 & $\mathrm{C}_{3} \mathrm{H}_{5} \mathrm{O}_{4}{ }^{-}$ \\
$\begin{array}{c}\text { oxo- } \mathrm{C}_{7} \\
\text { product }\end{array}$ & 175.0605 & 175.0612 & 4.00 & $\mathrm{C}_{7} \mathrm{H}_{11} \mathrm{O}_{5}^{-}$ \\
$\begin{array}{l}\text { oxo-C } \\
\text { product }\end{array}$ & 219.0496 & 219.0510 & 6.39 & $\mathrm{C}_{8} \mathrm{H}_{11} \mathrm{O}_{7}^{-}$ \\
$\begin{array}{l}\text { DMTA } \\
\text { acetic acid }\end{array}$ & 177.0399 & 177.0405 & 3.39 & $\mathrm{C}_{6} \mathrm{H}_{9} \mathrm{O}_{6}{ }^{-}$ \\
\hline
\end{tabular}

mass defect for the predicted formula in the anion identified $\{\mathrm{M}-\mathrm{H}\}^{-}$. There is an excellent agreement between the $\mathrm{m} / z$ detected and the theoretical values (Table 2 ). It was confirmed that acetoin at $m / z 87.0452$ (easily distinguished from PA) and lactic acid $(m / z 89.0244)$ were absent in the spectrum of the photolysis products. The analysis of the fragmentation patterns by tandem mass spectrometry (MS/MS) for the species in Table 2 is presented in the Supporting Information (Figure S4).

Two Dimensional NMR. Figure 4 shows the ${ }^{13} \mathrm{C}$ gCOSY spectrum for the photolysis of $97.88 \mathrm{mM}{ }^{13} \mathrm{C}$ labeled PA for a

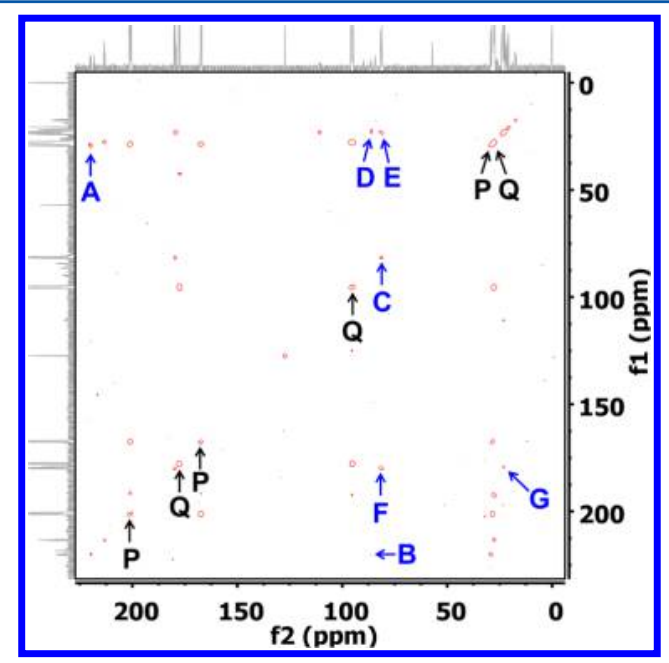

Figure 4. $150 \mathrm{MHz}{ }^{13} \mathrm{C}$ gCOSY NMR spectrum of $97.88 \mathrm{mM}$ fully labeled ${ }^{13} \mathrm{C}$ PA at $\mathrm{pD}=1.0$ photolyzed for $9 \mathrm{~min}$ for a $50.2 \%$ conversion. Cross peaks labeled A-G show carbon correlations for the oxo- $\mathrm{C}_{7}$ product. Diagonal peaks for unreacted keto and hydrate forms of PA are labeled with the letters $\mathrm{P}$ and $\mathrm{Q}$ respectively. All other conditions as presented for Figure 1.

$50.2 \%$ conversion, due to the low sensitivity of the NMR experiment. Additional one-dimensional ${ }^{13} \mathrm{C}$ NMR spectra for a $20 \%$ conversion is used to guide the assignment of the major product peaks in the spectrum for $50 \%$ conversion. Thus, Figure 4 is used with confidence for characterizing the major photoproducts, despite any possible contribution of secondary products to the spectrum. The corresponding one-dimensional ${ }^{13} \mathrm{C}$ NMR spectrum for the same sample is shown in Figure S5 with the peak assignment in Table S2 (Supporting Information).
In theory, the ${ }^{13} \mathrm{C}$ COSY experiment shows cross-peaks between carbons that are 1 to 3 bonds apart in the molecule, but in practice, the most intense signals come from 1 bond couplings. As expected, the most intense cross-peaks in Figure 4 are from the unreacted $\mathrm{PA}$, presenting ${ }^{13} \mathrm{C}$ resonances for the carbonyl and hydrate forms at 201.00; 177.82; 167.39; 95.39; 28.40; and 27.64 ppm (see Figure S5, Supporting Information). The diagonal peaks for the keto and hydrate forms of PA signals are respectively labeled with the letters $P$ and $Q$ in Figure 4. The new signals are apparent in the $-\mathrm{C}-\mathrm{O}(40-80$ $\mathrm{ppm}),-\mathrm{COOH}(155-185 \mathrm{ppm})$, and $\mathrm{C}=\mathrm{O}(185-220)$ regions, ${ }^{44}$ which is consistent with the functional groups present in the products depicted in Scheme 1.

The carbon backbone of the major oxo- $\mathrm{C}_{7}$ product in the mixture can be mapped out by the cross-peaks labeled A-G in blue in Figure 4. The most intense carbonyl cross-peak occurs at $\sim 220 \mathrm{ppm}$ and is therefore assigned to the oxo- $\mathrm{C}_{7}$ product. Figure 4 shows that this carbonyl is coupled to a $-\mathrm{CH}_{3}$ group at $\sim 29 \mathrm{ppm}$ (cross-peak A) and a $-\mathrm{C}-\mathrm{O}$ carbon ( $\sim 86 \mathrm{ppm}$, cross-peak B). This $-\mathrm{C}-\mathrm{O}$ carbon $(\sim 86 \mathrm{ppm})$ is in turn coupled to another $-\mathrm{C}-\mathrm{O}$ carbon $(\sim 81 \mathrm{ppm}$, cross-peak $\mathrm{C})$ and to a different $-\mathrm{CH}_{3}$ group at $23.18 \mathrm{ppm}$ (cross-peak D). Finally, this second $-\mathrm{C}-\mathrm{O}$ carbon $(\sim 81 \mathrm{ppm})$ is coupled to both a third $-\mathrm{CH}_{3}$ group at $23.06 \mathrm{ppm}$ (cross-peak E) and a $-\mathrm{COOH}$ at $\sim 180 \mathrm{ppm}$ (cross-peak F). A coupling between the $-\mathrm{COOH}$ carbon and the last $-\mathrm{CH}_{3}$ carbon $(23.04 \mathrm{ppm})$ is also observable in Figure 4 (cross-peak G). Assembling each of these carbon atoms by their couplings provides an unambiguous structure consistent with the oxo- $\mathrm{C}_{7}$ product in Scheme 1, which is the most abundant photoproduct in the chromatographic analyses. It is worth noting that the $-\mathrm{C}-\mathrm{O}$ signals could originate from ether or alcohol carbons. However, the lack of $\mathrm{C}-\mathrm{C}$ coupling between the $-\mathrm{COOH}(\sim 180 \mathrm{ppm})$ and the farther $-\mathrm{C}-\mathrm{O}$ group $(\sim 86 \mathrm{ppm})$ indicates that an oxygen linkage must exist between the two $-\mathrm{C}-\mathrm{O}$ carbons. In consequence, the $-\mathrm{COOH}$ carbon is three bonds away from the farther $-\mathrm{C}-\mathrm{O}$ carbon, rather than only two bonds, which diminishes the likelihood of observing the coupling under these conditions. Indeed, the previously registered gas phase FTIR spectrum of products covered by water signals ${ }^{29}$ must be related to this abundant species and is assigned here to the oxo$\mathrm{C}_{7}$ product (Table S1, Supporting Information).

The three unique carbons in DMTA can be observed in the one-dimensional ${ }^{13} \mathrm{C}$ NMR spectrum (Figure S5, Supporting Information) to occur at chemical shifts of 179.14, 84.34, and $21.77 \mathrm{ppm}$. Given the weaker signals expected for the lower [DMTA] in the mixture, cross-peaks are not seen for this species or the oxo- $\mathrm{C}_{8}$ product in the gCOSY spectrum.

Analysis of Carbonyls Treated with DNPH. Additional confirmation of the structures of the oxo- $\mathrm{C}_{7}$ product and dimethyltartaric acid is provided by UHPLC-MS analysis of reaction mixtures after derivatization with DNPH. The derivatization of mixtures with DNPH is the preferred analytical method for the separation and identification of carbonyls. Our previous work established that the mass spectrometer can easily detect the addition of $180.03 \mathrm{amu}$ to the $\mathrm{m} / \mathrm{z}$ value of the underivatized carbonyl containing species. ${ }^{5,29}$ This mass addition corresponds to $\mathrm{C}=\mathrm{O}$ group condensation with a bulky DNPH molecule with loss of water. Figure 5A shows the EIC from UHPLC-MS analysis of the $E$ and $Z$ hydrazone isomers of PA at $m / z$ 267.04. The hydrazone for acetoin would appear at $\mathrm{m} / z$ 267.07. However, spike additions of acetoin to final concentrations of $10.0 \mu \mathrm{M}$ before 


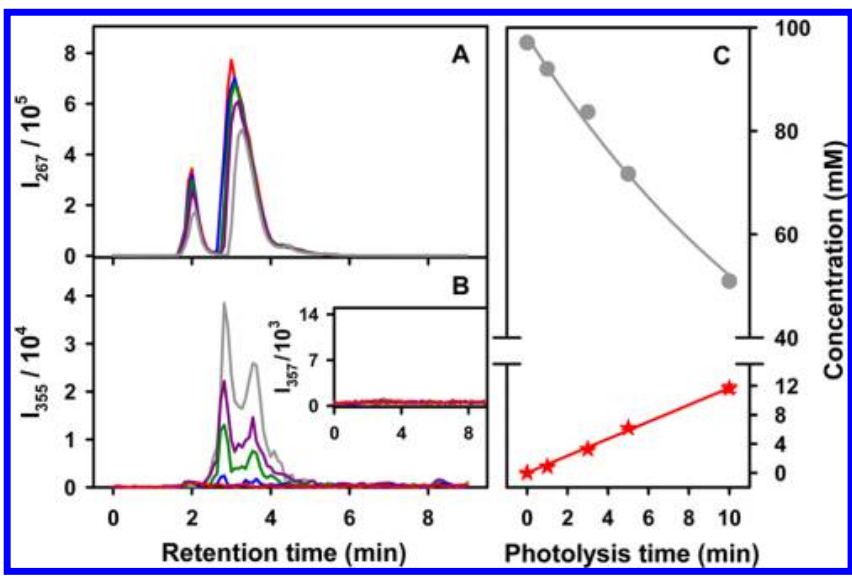

Figure 5. UHPLC-MS from DNPH hydrazones of (A) PA $(\mathrm{m} / z$ $267.04)$ and (B) oxo- $\mathrm{C}_{7}$ product $(\mathrm{m} / z$ 355.09) from an experiment with $[\mathrm{PA}]=97.1 \mathrm{mM}$ photolyzed during (red) 0, (blue) 1, (green) 3, (purple) 5, and (gray) $10 \mathrm{~min}$. Inset shows no hydrazone for DMTA $(m / z 357.07)$. (C) Time series for (gray circle) PA loss and (red star) oxo- $\mathrm{C}_{7}$ product formation from hydrazones in panels $\mathrm{A}$ and $\mathrm{B}$. All other conditions as presented for Figure 1.

derivatization confirm that this molecule is absent in the unspiked samples from photolysis. The EIC for $m / z 355.09$ in Figure $5 \mathrm{~B}$ corresponds to the hydrazone of the oxo- $\mathrm{C}_{7}$ product, while the absence of any peak at $\mathrm{m} / \mathrm{z} 357.07$ (see inset) confirms that DMTA does not possess a derivatizable carbonyl group.

The derivatization with DNPH performed on the photolyzed ${ }^{13} \mathrm{C}$ labeled PA is presented in Figure S6 (Supporting Information). With three heavy carbons, the $E$ and $Z$ hydrazones of ${ }^{13} \mathrm{C}$ labeled PA are observed at $\mathrm{m} / \mathrm{z} 270.05$, while the hydrazone for acetoin $\left(4 \times{ }^{13} \mathrm{C}\right)$ should be observed at $\mathrm{m} / z$ 271.09. The ${ }^{13} \mathrm{C}$ labeled PA hydrazones with an extra ${ }^{13} \mathrm{C}$ from the natural abundance enrichment expected for DNPH should be observed at $m / z 271.05$, which would be indistinguishable from acetoin. However, the percentage ratio of integrating the ion counts $\left(I_{m / z}\right)$ at $\mathrm{m} / z 271.05$ and 270.05 for these perfectly coeluting chromatographic peaks, $R_{271 / 270}=$ $100 \times \int_{0.85 \min }^{4.28 \min _{21}} I_{27.05} \mathrm{~d} t / \int_{0.85 \mathrm{~min}}^{4.28 \min _{2}} I_{270.05} \mathrm{~d} t$, in Figure S6 (Supporting Information) yields an average of $1.54( \pm 0.01) \%$ before and after $10 \mathrm{~min}$ of irradiation. Thus, any contribution to the peak with $m / z 271.05$ must be due to the natural isotopic abundance contribution of $\mathrm{DNPH}$ to the ${ }^{13} \mathrm{C}$ labeled PA hydrazone, which is predicted to be $1.54 \%$, matching $R_{271 / 270}$. Finally, a trace production of acetaldehyde at $\mathrm{m} / z 225.05$ (Figure S6, Supporting Information) becomes evident during UHPLC-MS analysis of hydrazones from ${ }^{13} \mathrm{C}$ labeled PA. Because acetaldehyde is a common ambient air pollutant, ${ }^{47,48}$ the solution with DNPH can easily scavenge ${ }^{12} \mathrm{C}$ acetaldehyde forming its hydrazone. Thus, the experiment detecting its ${ }^{13} \mathrm{C}$ isotopologue during the photolysis of ${ }^{13} \mathrm{C} \mathrm{PA}$ provides additional support for the photochemical production of acetaldehyde. The presence of a trace of acetaldehyde confirms that $\mathrm{Y}^{\bullet}$ is an intermediate radical in the mechanism.

Considering a photochemical mechanism for conversion below 30\% in Figure 1, the average concentration ratio [oxo$\left.\mathrm{C}_{7}\right] /\left[\right.$ oxo- $\left.\mathrm{C}_{8}\right] \approx 7.4$ can be rationalized to arise from the decarboxylation of the unstable $\beta$-ketocarboxylic acid oxo- $\mathrm{C}_{8}$ intermediate into the oxo- $\mathrm{C}_{7}$ product. Furthermore, the derivatization conditions favor the decarboxylative loss of any remaining oxo- $\mathrm{C}_{8}$ product. Figure $5 \mathrm{C}$ shows how the hydrazones of PA and the oxo- $\mathrm{C}_{7}$ product decay and grow, respectively, in general agreement with Figure $1 \mathrm{~B}$.

Although acetoin was proposed as a major photoproduct in one of the first studies of PA direct photolysis in water, ${ }^{28}$ it was later explained that under high temperature $\mathrm{GC}$ conditions the oxo- $\mathrm{C}_{7}$ and oxo- $\mathrm{C}_{8}$ products decompose into acetoin. ${ }^{2}$ Additionally, we have established an upper limit for the yield of acetoin photoproduction, if any could be detected, to be below $0.006 \%$ or at the trace level. ${ }^{29}$ Despite the chromatographic results in Figure 4 that verify our previous results showing a lack of acetoin in the photoproduct mixture, ${ }^{2,21,29}$ it is critical to further explore this issue using the NMR-based techniques used to support its presence. ${ }^{3,26}$ Below, we use the method of standard addition to accurately reassign the spectroscopic features in the ${ }^{1} \mathrm{H}$ NMR spectrum of the photolysis mixture inaccurately attributed to acetoin.,26

Qualitative and Quantitative ${ }^{1} \mathrm{H}$ NMR Analysis. In order to quantify each product by ${ }^{1} \mathrm{H}$ NMR, the entire spectrum must be first assigned. While the chromatographic analysis indicates that only three products largely dominate the composition of the reaction mixture, the ${ }^{1} \mathrm{H}$ NMR spectrum is much more complex due to the presence of diastereomers for each product, making the assignment of all resonances difficult. In order to facilitate the assignment of the spectrum, a photolysis with more concentrated reagent was performed for air saturated PA solution of initial concentration $[\mathrm{PA}]_{0}=322$ $\mathrm{mM}$ at $\mathrm{pH}=1$ up to a $20.3 \%$ conversion. The assignment of this $600 \mathrm{MHz}{ }^{1} \mathrm{H}$ NMR spectrum is available in Table S3 (Supporting Information).

Figure 6 shows ${ }^{1} \mathrm{H}$ NMR spectra for an experiment with a solution of $102.4 \mathrm{mM}$ PA before irradiation (panel A), after

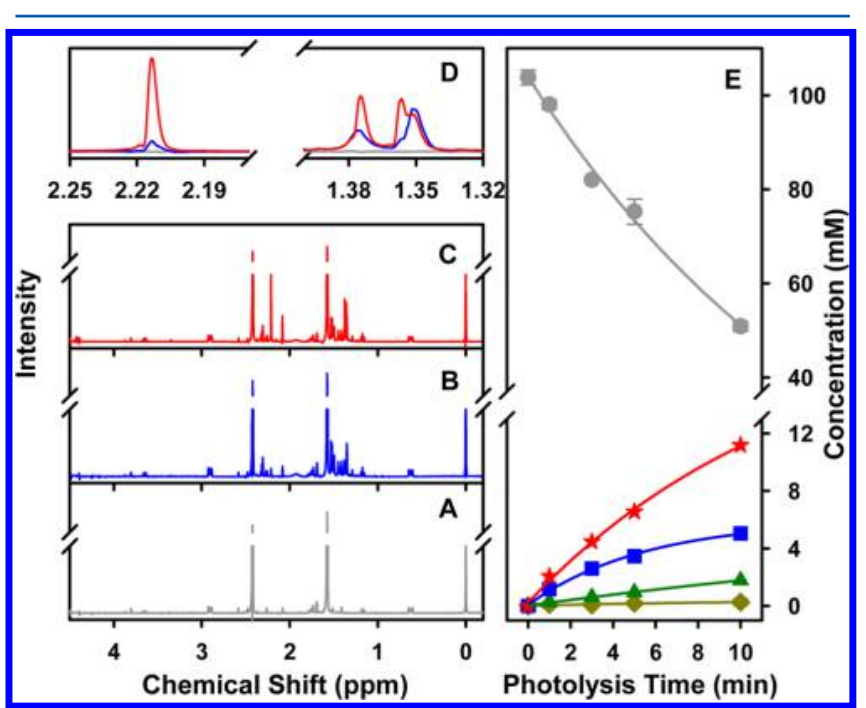

Figure 6. ${ }^{1} \mathrm{H}$ NMR spectra of $102.4 \mathrm{mM}$ PA solution (A) before photolysis, (B) for $15.5 \%$ conversion at $\lambda \geq 305 \mathrm{~nm}$, and (C) the spectrum in $\mathrm{B}$ spiked to [acetoin $]_{\text {final }}=4.06 \mathrm{mM}$. (D) Close up of spectra in panels A, B, and C. (E) Time series of (gray circle) PA loss, (red star) oxo- $\mathrm{C}_{7}$ product, (blue square) DMTA, (green triangle) oxo$\mathrm{C}_{8}$ product, and (gold diamond) acetic acid. All other conditions as presented for Figure 1.

photolysis for a $15 \%$ conversion (panel B), the same postphotolysis sample in panel B after spiking to [acetoin $]_{\text {final }}=4.06$ $\mathrm{mM}$ (panel C). Figure 6D presents a close-up view from the regions where acetoin signals should be observed. An acetoin standard in $\mathrm{D}_{2} \mathrm{O}$ referenced to DSS displays three signals: $\delta$ 
$1.37(\mathrm{~d}, J=6.9 \mathrm{~Hz}, 3 \mathrm{H}), 2.21(\mathrm{~s}, 3 \mathrm{H}), 4.42(\mathrm{q}, 1 \mathrm{H})$. Figure $6 \mathrm{D}$ clearly shows that while $\delta 2.21$ (s) matches quite well with a photoproduct peak, the doublet centered at $\delta 1.37$ (d) does not, implying that different species are the main contributors to both associated signals under consideration.

Hypothetically, the maximum concentration of acetoin would be constrained by the area from the singlet at $\delta 2.21$, which yields $238 \mu \mathrm{M}$ for $15.4 \%$ PA conversion. Given the much lower threshold for the concentration of acetoin set chromatographically, ${ }^{29}$ it is unlikely that the small peak at $\delta 2.21$ could be due to acetoin. Instead, the resonance at $2.21 \mathrm{ppm}$ can be explained by a methyl group neighboring the $\mathrm{C}=\mathrm{O}$ in the oxo$\mathrm{C}_{8}$ product (see structure in Scheme 1 with the $-\mathrm{CH}_{3}$ group in pink font).

Computational predictions of the ${ }^{1} \mathrm{H}$ NMR spectrum for the oxo- $\mathrm{C}_{8}$ product place the analogous $-\mathrm{CH}_{3}$ singlet at $\delta 2.16$ near the signal of interest. The very intense singlet for the $-\mathrm{CH}_{3}$ group bound to the $\mathrm{C}=\mathrm{O}$ of the abundant oxo- $\mathrm{C}_{7}$ product is found at $\delta 2.31$, which cannot be confused with the intermediate species observed in the spectrum at $\delta 2.21$. Additionally, we must note that the oxo- $\mathrm{C}_{8}$ and oxo- $\mathrm{C}_{7}$ products correctly account for the other ${ }^{1} \mathrm{H}$ NMR peaks at $\sim \delta 4.40$ (q) previously assigned to acetoin and lactic acid. ${ }^{26}$ The two oxo products also explain the features in the infrared spectrum of the photolysis products that partitioned to the gas phase (see Table S1, Supporting Information), ${ }^{29}$ which were mistakenly assigned to acetoin. ${ }^{26}$ An interesting outcome from the spike addition of acetoin, purposely designed to increase the area under $\delta 2.21(\mathrm{~s})$ of the photolyzed samples between 1 and 3 times, is that it can be used to quantify the perfectly overlapping oxo- $\mathrm{C}_{8}$ photoproduct by qNMR. The quantification of all species by qNMR (Figure $6 \mathrm{E}$ ), including the low production of the oxo- $\mathrm{C}_{8}$ intermediate, agrees well with the results from IC-MS in Figure $1 \mathrm{~B}$.

The ${ }^{1} \mathrm{H}$ NMR study is also capable of evaluating whether acetic acid is a minor photoproduct or not, as proposed elsewhere. ${ }^{3,26}$ This analysis has direct implications for assessing if lactic acid is present and at a relevant concentration in the photolyzed mixture. While lactic and acetic acids have been proposed to be produced by a reaction channel in a 1:1 ratio, a second source of acetic acid has been postulated in the presence of dissolved $\mathrm{O}_{2}{ }^{3}$. Thus, the quantified concentration of acetic acid in Figure $6 \mathrm{E}$ should serve as an upper limit for the concentration of lactic acid, if any is produced, making the quantification of lactic acid of lesser importance. Noticeably, a small amount of acetic acid is observed while the [PA] drops. A simple comparison at $3 \mathrm{~min}$ of irradiation, corresponding to a $19.8 \%$ conversion, indicates that the scarce oxo- $C_{8}$ photoproduct is 6.2 times more abundant than acetic acid. In addition, lactic acid was spiked in photolyzed samples for qualitative purposes (Figure S7, Supporting Information). While the chemical shift of peaks in the $-\mathrm{CH}_{3}$ region $(\delta \sim$ 1.40 to 1.44 ) of the photolyzed mixture do not overlap well with the signal in lactic acid, the area for the photoproducts is also considerably larger than acceptable for the stoichiometric constraint for lactic acid discussed already. The previous observation is consistent with the lack of lactic acid peaks during IC-conductivity-MS analysis.

Reaction Mechanism with Formation of the Oxo- $\mathrm{C}_{8}$ Intermediate. The data presented above showing an oxo- $\mathrm{C}_{8}$ photoproduct for the first time provides strong support for the mechanism in Scheme 1. Briefly, the photochemical process begins with a production of triplet excited state $\mathrm{PA}^{*}$ in overall reaction $\mathrm{R} 1 \mathrm{a}+\mathrm{R} 1 \mathrm{~b}$ (Scheme 1 ), which could be thermally lost via reaction $\mathrm{R} 2$. $\mathrm{PA}^{*}$ undergoes proton-coupled electron transfer (PCET) with a ground state molecule in concerted reaction $\mathrm{R} 3$ to yield the ketyl radical $\mathrm{K}^{\bullet}$ and an acyloxy radical $\mathrm{X}^{\bullet}$. The rapid decomposition of $\mathrm{X}^{\bullet}$ releases $\mathrm{CO}_{2}(\mathrm{~g})$ and the acetyl radical $\mathrm{Y}^{\bullet}$ in a few picoseconds via reaction $\mathrm{R} 4 \mathrm{a}^{2,21,23}$ which gets hydrated via reaction $\mathrm{R} 4 \mathrm{~b}$ with a rate constant $k_{4 \mathrm{~b}}=$ of $2 \times 10^{4} \mathrm{~s}^{-1}$. ${ }^{49}$ In the presence of dissolved $\mathrm{O}_{2}$, the strongly reducing $\mathrm{Y}^{\bullet}$ radical $^{49}$ generates acetic acid and another equivalent of $\mathrm{HO}_{2}{ }^{\bullet}$ in the sequence of reactions $\mathrm{R} 5 \mathrm{a}, \mathrm{R} 5 \mathrm{~b}$ with an overall rate constant $k_{5}=7.7 \times 10^{8} \mathrm{M}^{-1} \mathrm{~s}^{-1}$. ${ }^{\circ}$ Alternatively $\mathrm{Y}^{\bullet}$ can reduce the abundant ground state PA stoichiometrically producing $\mathrm{K}^{\bullet}$ and acetic acid. The recombination of two $\mathrm{K}^{\bullet}$ radicals in reaction $\mathrm{R} 6$ forming DMTA, a major product, proceeds with a rate constant $k_{6} \approx 2 \times 10^{9} \mathrm{M}^{-1}$ $\mathrm{s}^{-1}$. Reaction R7a also competes for the fate of $\mathrm{K}^{\bullet}$ radicals by generating a peroxy radical $\mathrm{KO}_{2}{ }^{\bullet}$ in the presence of dissolved $\mathrm{O}_{2}$, the rate constant of which is unknown at $\mathrm{pH} 1$ but has been reported at $\mathrm{pH} 7: k_{7 \mathrm{a}}=2.6 \times 10^{9} \mathrm{M}^{-1} \mathrm{~s}^{-1} \cdot{ }^{51}$ The radical $\mathrm{KO}_{2}{ }^{\bullet}$ participates in a null cycle by decomposing back into PA and hydroperoxyl radical, $\mathrm{HO}_{2}{ }^{\bullet}$ in reaction $\mathrm{R} 7 \mathrm{~b}$.

The high reactivity of the photogenerated radicals tends to deplete $\mathrm{O}_{2}(\mathrm{aq})$ from the solution quickly. However, up to $90 \%$ regeneration of $\mathrm{PA}$ was observed via reaction $\mathrm{R} 7$ that traps $\mathrm{K}^{\bullet}$ in the presence of $\left[\mathrm{O}_{2}(\mathrm{aq})\right]=32 \mu \mathrm{M}$ from continuous air sparging (as monitored before for glyoxylic acid) ${ }^{5}$ compared to anoxic conditions. While the recycling of $\mathrm{K}^{\bullet}$ proceeds, $\mathrm{Y}^{\bullet}$ becomes more available for the generation of acetic acid. Similarly, the respective generation of DMTA, the oxo- $\mathrm{C}_{7}$ product, and the oxo- $\mathrm{C}_{8}$ product still proceeds in the presence of air, although slower by 37, 285, and 94 times than under anoxic conditions. Based on Scheme 1, the initial photolytic loss rate $R_{0}=1.46 \times 10^{-5} \mathrm{M} \mathrm{s}^{-1}$ for $100 \mathrm{mM}$ PA (Figure S9, Supporting Information) produces stoichiometric amounts of $\mathrm{K}^{\bullet}$ and $\mathrm{Y}^{\bullet}$ radicals. Under nondepleted $\mathrm{O}_{2}$ conditions, the measured initial production rates can be used to estimate $\left[\mathrm{K}^{\bullet}\right]$ $=\sqrt{\left(\text { rate } R_{0}-\text { rate } R_{8}-\text { rate } R_{9}\right) / k_{6}}=2.36 \times 10^{-8} \mathrm{M}$. The previous value needs to be multiplied by 9.42 (see the regeneration of PA indicated above under nondepleted $\mathrm{O}_{2}(\mathrm{aq})$ conditions) to estimate the total steady state $\left[\mathrm{K}^{\bullet}\right]_{\mathrm{ss}}=1.71 \times$ $10^{-7} \mathrm{M}$. The competitive pathway for trapping $\mathrm{K}^{\bullet}$ in the presence of $\left[\mathrm{O}_{2}(\mathrm{aq})\right]=130 \mu \mathrm{M}$ proceeds with an 80 times drop in oxo- $\mathrm{C}_{7}$ production. Therefore, the ratio of reaction rates from oxygen scavenging of $\mathrm{K}^{\bullet}$ with rate constant $k_{7 \mathrm{a}}$ to the production of the oxo- $\mathrm{C}_{7}$ product must be $\left(\mathrm{d}\left[\mathrm{KO}_{2}^{\circ}\right] / \mathrm{d} t\right) /$ $\left(\mathrm{d}\left[\right.\right.$ oxo- $\mathrm{C}_{7}$ product $\left.] / \mathrm{d} t\right)=k_{7 \mathrm{a}}\left[\mathrm{K}^{\bullet}\right]_{\mathrm{ss}, \mathrm{O}_{2}}\left[\mathrm{O}_{2}(\mathrm{aq})\right] /\left(k_{6}\left[\mathrm{~K}^{\bullet}\right]_{\mathrm{ss}, \mathrm{O}_{2}}^{2}\right)$ $=79$. Thus, by solving for $k_{7 \mathrm{a}}$ in eq 3

$$
k_{7 \mathrm{a}}=\frac{79 k_{6}\left[\mathrm{~K}^{\bullet}\right]_{\mathrm{ss}, \mathrm{O}_{2}}}{\left[\mathrm{O}_{2}(\mathrm{aq})\right]}
$$

a rough estimate of $k_{7 \mathrm{a}}=1.22 \times 10^{9} \mathrm{M}^{-1} \mathrm{~s}^{-1}$ is obtained at $\mathrm{pH}$ 1. Therefore, the advanced quantification methods presented here allow one to estimate a reasonable value as compared to similar radicals that scavenge $\mathrm{O}_{2}(\mathrm{aq})$ with a rate constant $k_{\mathrm{sc}} \sim$ $1 \times 10^{9} \mathrm{M}^{-1} \mathrm{~s}^{-1}$. ${ }^{52}$ Future efforts should experimentally determine $k_{7 \mathrm{a}}$.

The strong oxidant $\mathrm{HO}_{2}{ }^{\bullet}$ from reactions such as $\mathrm{R} 7 \mathrm{~b}$ can self-disproportionate to form $\mathrm{H}_{2} \mathrm{O}_{2}$ and $\mathrm{O}_{2}$ in the absence of transition metal ions. The produced $\mathrm{H}_{2} \mathrm{O}_{2}$ can be photolyzed at $\lambda \leq 365 \mathrm{~nm},{ }^{53}$ providing a potential source of $\mathrm{HO}^{\circ}$. Acetic acid can also result from the reaction of $\mathrm{PA}+\mathrm{HO}^{\bullet}$ with second 
order rate constant $k_{\mathrm{PA}+\mathrm{HO}}{ }^{*}=3.2 \times 10^{8} \mathrm{M}^{-1} \mathrm{~s}^{-1}$, via an alkoxy radical intermediate. ${ }^{52}$ In addition, the reaction of $\mathrm{PA}$ with $\mathrm{HO}^{\circ}$ has been proposed to generate acetic, formic, glyoxylic, and oxalic acids. ${ }^{17,18}$ However, only acetic acid is observed here, indicating that oxidation by $\mathrm{HO}^{\bullet}$ generated in situ is not a competitive pathway during direct photolysis. Ultimately, the fate of any produced $\mathrm{HO}_{2}{ }^{\bullet}$ would be to undergo decomposition into $\mathrm{O}_{2}$ and $\mathrm{H}_{2} \mathrm{O} .^{53}$ A reaction of increasing importance at higher PA concentrations is the addition of $\mathrm{K}^{\circ}$ to the $\mathrm{C}=\mathrm{O}$ of a neutral PA molecule (reaction R8a), forming the radical $\mathrm{C}^{\bullet}$. Finally, the radicals $\mathrm{C}^{\bullet}$ and $\mathrm{Y}^{\bullet}$ must then combine to form the oxo- $\mathrm{C}_{8}$ photoproduct via reaction $\mathrm{R} 8 \mathrm{~b}$, which undergoes a typical $\beta$-ketocarboxylic acid decarboxylation with rate constant $k_{9}=1.21 \times 10^{-3} \mathrm{~s}^{-1}$, into the oxo- $\mathrm{C}_{7}$ product in reaction $\mathrm{R} 9$. Previously proposed pathways to acetoin and lactic acid production $^{3,26}$ are not included in this scheme because of the demonstrated lack of evidence for their formation.

Evaluation of the Reaction Mechanism from Measured Quantum Yields. The steady state concentration of excited state pyruvic acid, $\left[\mathrm{PA}^{*}\right]_{s s}$, can be inferred by balancing out its measured initial rate of production with an upper limit set by the measured loss of PA, $k_{h v}[\mathrm{PA}]_{0}$, against the loss of $\mathrm{PA}^{*}$ by thermal processes in reaction $\mathrm{R} 2$ and from its bimolecular reaction with ground state PA by reaction R3 (Scheme 1). For practical purposes, there is no difference if the (indistinguishable) photoinduced bimolecular process represents a hydrogen atom transfer, an electron transfer, or PCET. Thus, from $k_{h \nu}[\mathrm{PA}]_{0}=k_{2}\left[\mathrm{PA}^{*}\right]+k_{3}\left[\mathrm{PA}^{*}\right][\mathrm{PA}]_{0}$, it is possible to obtain at variable $[\mathrm{PA}]_{0}$ :

$$
\left[\mathrm{PA}^{*}\right]_{\mathrm{ss}}=\frac{k_{h \nu}[\mathrm{PA}]_{0}}{k_{2}+k_{3}[\mathrm{PA}]_{0}}
$$

Figure S8 (Supporting Information) shows that the photolytic rate in eq $4, k_{h v}[\mathrm{PA}]_{0}$, depends linearly on the photon absorption by aqueous PA solution $\left(I_{\mathrm{a}}\right)$ with a slope of $\sim 2$. Indeed, Figure S8 indicates that $\Phi_{-\mathrm{PA}} \approx 2$ or that each $\mathrm{PA}^{*}$ produced per photon absorbed consumes an additional molecule of PA in a highly efficient bimolecular process. The $\Phi_{-\mathrm{PA}}$ should not be confused with the photodecarboxylation quantum yield of aqueous PA, $\Phi_{-\mathrm{CO}_{2}}=0.78 .^{21}$ While $\Phi_{-\mathrm{CO}_{2}}$ accounts for $\sim 50 \%$ of the evolution of $\mathrm{CO}_{2}(\mathrm{~g})$ from the primary decomposition of $\mathrm{X}^{\bullet}$ per photon absorbed, the secondary decarboxylation of the oxo- $\mathrm{C}_{8}$ product must contribute the other $\sim 28 \%$ of this gas. Thus, the missing $\sim 22 \%$ of produced $\mathrm{K}^{\bullet}$ radical must recombine to produce DMTA, which does not emit $\mathrm{CO}_{2}(\mathrm{~g})$. For experiments with $[\mathrm{PA}]_{0} \geq 4 \mathrm{mM}, I_{a}$ is given by $^{2}$

$$
I_{a}=I_{0}\left(1-\mathrm{e}^{-2.303 \varepsilon l[\mathrm{PA}]_{0}}\right)
$$

$I_{a}$ only varies with $[\mathrm{PA}]_{0}$, because the incident photon rate, $I_{0}=$ $1.14 \times 10^{-5} \mathrm{M} \mathrm{s}^{-1}$, the molar absorptivity of PA $\left(\varepsilon=11.3 \mathrm{M}^{-1}\right.$ $\left.\mathrm{cm}^{-1}\right),{ }^{28}$ and the optical path length of the NMR tube $(l=$ $0.424 \mathrm{~cm})$ are constants. Therefore, by substituting $k_{h v}[\mathrm{PA}]_{0} \approx$ $2 I_{a}$ in eq 3 :

$$
\left[\mathrm{PA}^{*}\right]_{\mathrm{ss}}=\frac{2 I_{a}}{k_{2}+k_{3}[\mathrm{PA}]_{0}}
$$

Assuming this simplified reaction scheme, for each photolyzed molecule of PA generating the stoichiometric amount of ketyl and acetyl radicals, $\mathrm{PA}+h \nu \rightarrow \mathrm{K}^{\bullet}+\mathrm{Y}^{\bullet}$, provides a means to solve the steady state concentration of ketyl radicals, $\left[\mathrm{K}^{\bullet}\right]_{\mathrm{ss}}$ in the system. Thus, balancing out the measured initial rate of PA loss to the initial rate of generation of product consuming $\mathrm{K}^{\bullet}$ (observed from the channels $\mathrm{R} 6+\mathrm{R} 8+\mathrm{R} 9$ in Scheme 1) indicates that

$$
\sum \text { rate of product formation }=k_{3}\left[\mathrm{PA}^{*}\right][\mathrm{PA}]_{0}
$$

The initial rate of generation of product and loss of PA are presented in Figure S9 (Supporting Information) for a $\leq 20 \%$ conversion. By substituting [PA*] from eq 6 in eq 7 , and reordering, it is apparent that

$$
\begin{aligned}
\sum \Phi_{\text {Product }} & =\frac{\sum \text { rate of product formation }}{I_{a}} \\
& =\frac{2[\mathrm{PA}]_{0}}{k_{2} k_{3}^{-1}+[\mathrm{PA}]_{0}}
\end{aligned}
$$

Thus, the sum of the corresponding photochemical quantum yields for the oxo- $\mathrm{C}_{7}$ product $\left(\Phi_{\text {oxo-C }}\right), 2,3$-dimethyltartaric acid $\left(\Phi_{\mathrm{DMTA}}\right)$, and the oxo- $\mathrm{C}_{8}$ product $\left(\Phi_{\text {oxo-C }}\right), \sum \Phi_{\text {product }}$ depends on $[\mathrm{PA}]_{0}$ as described by the hyperbola in eq 8 . The $\sum \Phi_{\text {product }}$ is calculated from the initial formation rates divided by the absorbed photon rate from eq 5 . Figure 7 shows the sum

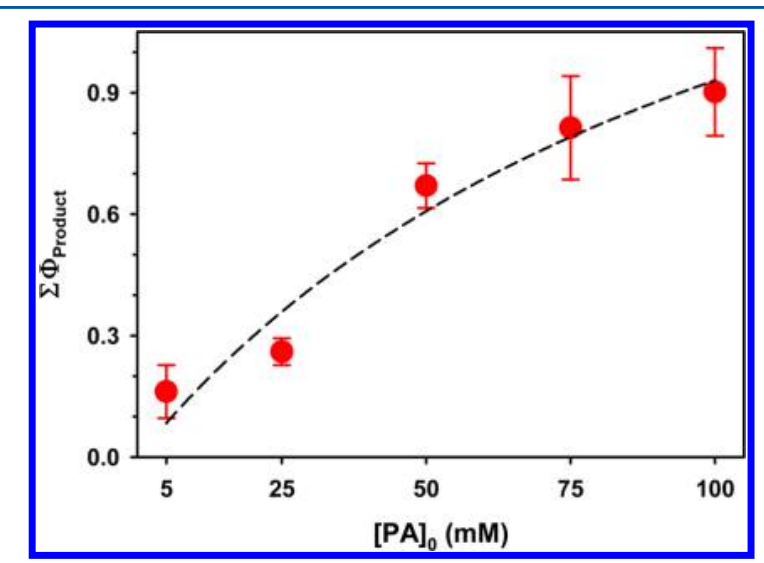

Figure 7. Effect of initial concentration of pyruvic acid $\left([\mathrm{PA}]_{0}\right)$ on normalized sum of the quantum yields for the oxo- $\mathrm{C}_{7}$ product, DMTA, and the oxo- $C_{8}$ product $\sum \Phi_{\text {product }}$ during the direct photolysis of aqueous solutions at $\mathrm{pH}=1$ and $298 \mathrm{~K}$.

of the quantum yields for the three products $\sum \Phi_{\text {product }} \mathrm{vs}[\mathrm{PA}]_{0}$ for the interval 5-100 $\mathrm{mM}$ measured using neutral density filters that reduce the total photon flux to $10.64 \%$.

The general behavior of $\sum \Phi_{\text {product }}$ vs $[\mathrm{PA}]_{0}$ in Figure 7 is fitted with the hyperbola $\sum \Phi_{\text {product }}=1.99[\mathrm{PA}]_{0} /(113.2+$ $\left.[\mathrm{PA}]_{0}\right)$ with $r^{2}=0.952$ and concentration in $\mathrm{mM}$ units. The branching ratio for the production of the oxo- $\mathrm{C}_{7}+$ oxo- $\mathrm{C}_{8}$ products grows faster than for DMTA for increasing $[\mathrm{PA}]_{0}$ (Figure S9, Supporting Information). The previous observation is expected for the given competition between the production rate of the oxo- $\mathrm{C}_{8}$ and oxo- $\mathrm{C}_{7}$ products involving radical addition of $\mathrm{K}^{\bullet}$ to a molecule of PA versus the recombination of two $\mathrm{K}^{\bullet}$ radicals forming DMTA.

\section{CONCLUSIONS}

The processing of organic species in aqueous secondary organic aerosols is an important matter. ${ }^{1,54}$ The photolysis rate in the aqueous phase $\left(j_{\text {aq }}\right)$ can be estimated from eq 9 


$$
j_{\mathrm{aq}}=\int F_{\mathrm{A}}(\lambda) \Phi(\lambda) \sigma(\lambda) \mathrm{d} \lambda
$$

using the measured $\Phi_{-\mathrm{PA}} \approx 2$, the variable actinic flux $F_{\mathrm{A}}(\lambda)$ at the surface for a solar zenith angle (SZA) of $40^{\circ}$ and a surface albedo $(\alpha)$ of $30 \%,{ }^{55}$ and the cross section of PA $\sigma(\lambda)$ extracted from a $100 \mathrm{mM}$ solution. For the environmental conditions defined, the reciprocal of the estimated $j_{\mathrm{aq}}=7.7 \times 10^{-4} \mathrm{~s}^{-1}$ can be used to report the lifetime of aqueous PA against loss by photolysis, $\tau_{\mathrm{aq}, \mathrm{h} \nu} \approx 21.7 \mathrm{~min}$. The aqueous phase loss of PA against expected urban cloud droplets ${ }^{56}$ with $\left[\mathrm{HO}^{\bullet}(\mathrm{aq})\right]=1 \times$ $10^{-13}$ to $1 \times 10^{-14} \mathrm{M}$ proceeds with a rate constant $k_{\mathrm{aq}, \mathrm{PA}+\mathrm{HO}}=$ $1.2 \times 10^{8} \mathrm{M}^{-1} \mathrm{~s}^{-1,57}$ with a comparatively long lifetime $\tau_{\text {aq,PA+OH }} \approx 0.96$ to 9.6 days, respectively. Instead, the gas phase photolysis of PA proceeds only 1.9-times faster than in water, as integrated for a unity quantum yield under the same SZA, $\alpha$, and altitude defined above. ${ }^{58}$ However, the reactivity in the gas phase should be of lesser importance because PA partitions quickly to the particle phase coexisting in hydration equilibrium with 2,2-dihydroxypropanoic acid. ${ }^{20}$ Combining the rate constant for the gas phase reaction $\mathrm{PA}+{ }^{\bullet} \mathrm{OH}$, a $k_{\mathrm{gas}, \mathrm{PA}+\mathrm{OH}}=$ $1.2 \times 10^{-13} \mathrm{~cm}^{3}$ molecule $^{-1} \mathrm{~s}^{-1,59}$ with $\left[\mathrm{HO}^{\bullet}(\mathrm{g})\right]_{\text {daytime }} 1.6 \times$ $10^{6}$ molecules $\mathrm{cm}^{-3}$, yields such a long lifetime, $\tau_{\mathrm{gas}, \mathrm{PA}+\mathrm{OH}} \approx 2.0$ months, that the importance of this process can be disregarded.

A combination of analytical methods support a photochemical mechanism where $\mathrm{PA}, \mathrm{K}^{\bullet}$, and $\mathrm{Y}^{\bullet}$ radicals play an important role in water, generating products with large $\mathrm{O}: \mathrm{C}$ ratio. Particularly, the chemical identification of the oxo- $\mathrm{C}_{8}$ product proves a radical-radical termination reaction involves the participation of $\mathrm{Y}^{\bullet}$. Additional support for a mechanism with the participation of $\mathrm{Y}^{\bullet}$ is provided by the small production of acetic acid in the presence of dissolved $\mathrm{O}_{2}(\mathrm{~g})$ and the detection of trace levels of acetaldehyde. In addition, this work demonstrates the importance of quality assurance when characterizing a complex reaction mixture to prevent mischaracterizing spectroscopic features for species such as acetoin and lactic acid. The work also serves as a model study recommending to others that (1) primary photoproducts should be preferably identified for maximum reactant conversions of $\sim 20-30 \%$, and (2) using more than one method of analysis is a preferred experimental practice.

The high reactivity of the photogenerated radicals tends to deplete $\mathrm{O}_{2}$ (aq) from the solution quickly. However, in the presence of dissolved $\mathrm{O}_{2}$, the loss of PA proceeds more slowly than under anoxic conditions, suggesting the importance of the null cycle via reaction $\mathrm{R} 7$ to trap $\mathrm{K}^{\bullet}$ and regenerate the reactant, while $\mathrm{Y}^{\bullet}$ becomes more available for the generation of acetic acid. Finally, simple $\alpha$-ketocarboxylic acids such as PA and glyoxylic acid are a potential source of complex SOA generation with common radical intermediates, which are produced by dissimilar photochemical initiation steps. ${ }^{5}$ Overall, the inclusion of direct photolysis for this class of compounds in atmospheric models should reduce the uncertainty associated with SOA sources in current models.

\section{ASSOCIATED CONTENT}

\section{(S Supporting Information}

The Supporting Information is available free of charge on the ACS Publications website at DOI: 10.1021/acs.jpca.6b11916.

Additional experimental details, additional figures including mass spectra, UHPLC-MS, and NMR, and data tables (PDF)

\section{AUTHOR INFORMATION}

\section{Corresponding Author}

*E-mail: marcelo.guzman@uky.edu, Phone: (859)323-2892.

ORCID

Marcelo I. Guzman: 0000-0002-6730-7766

\section{Notes}

The authors declare no competing financial interest.

\section{ACKNOWLEDGMENTS}

M.I.G. thanks research funding from the National Science foundation under NSF CAREER award CHE-1255290. A.J.E. acknowledges support by the NASA Earth and Space Science Fellowship (NESSF) Program.

\section{ABBREVIATIONS}

DHPA, 2,2,-dihydroxypropanoic acid; DMTA, 2,3-dimethyltartaric acid; DNPH, 2,4-dinitrophenylhydrazine; DSS, 3(trimethylsilyl)-1-propanesulfonic acid sodium salt; EIC, extracted ion chromatogram; $\mathrm{K}^{\bullet}$, ketyl or lactic acid radical; $K_{\text {hyd }}$ carbonyl hydration equilibrium constant; $K_{\mathrm{H}}$, Henry's law constant; KIE, kinetic isotope effect; oxo- $\mathrm{C}_{8}$ product, 2-(1carboxy-1-hydroxyethoxy)-2-methyl-3-oxobutanoic acid; oxo$\mathrm{C}_{7}$ product, 2-(3-oxobutan-2-yloxy)-2-hydroxypropanoic acid; $\mathrm{PA}$, pyruvic acid; ss, steady state; $\mathrm{PA}^{*}$, triplet excited state pyruvic acid; $\mathrm{X}^{\bullet}$, acyloxy radical; $\mathrm{Y}^{\bullet}$, acetyl radical; $\mathrm{KO}_{2}^{\bullet}$, lactic acid peroxyl radical; $\delta$, chemical shift; $\Phi$, quantum yield

\section{REFERENCES}

(1) Ervens, B. Modeling the processing of aerosol and trace gases in clouds and fogs. Chem. Rev. 2015, 115, 4157-4198.

(2) Guzman, M. I.; Colussi, A. J.; Hoffmann, M. R. Photoinduced

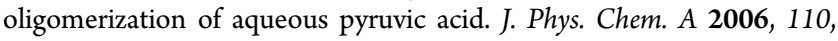
3619-3626.

(3) Reed Harris, A. E.; Ervens, B.; Shoemaker, R. K.; Kroll, J. A.; Rapf, R. J.; Griffith, E. C.; Monod, A.; Vaida, V. Photochemical kinetics of pyruvic acid in aqueous solution. I.Phvs. Chem. A 2014, 118, 85058516.

(4) Rincón, A. G.; Guzmán, M. I.; Hoffmann, M. R.; Colussi, A. J. Optical absorptivity versus molecular composition of model organic aerosol matter. I. Phys. Chem. A 2009, 113, 10512-10520.

(5) Eugene, A. J.; Xia, S.-S.; Guzman, M. I. Aqueous photochemistry of glyoxylic acid. I. Phys. Chem. A 2016, 120, 3817-3826.

(6) Rincón, A. G.; Guzmán, M. I.; Hoffmann, M. R.; Colussi, A. J. Thermochromism of model organic aerosol matter. I.Phvs. Chem. Lett. 2010, 1, 368-373.

(7) Souza, S. R.; Vasconcellos, P. C.; Carvalho, L. R. F. Low molecular weight carboxylic acids in an urban atmosphere: Winter measurements in Sao Paulo City, Brazil. Atmos. Environ. 1999, 33, $2563-2574$

(8) Andreae, M. O.; Browell, E. V.; Garstang, M.; Gregory, G.; Harriss, R.; Hill, G. F.; Jacob, D. J.; Pereira, M.; Sachse, G.; Setzer, A.; et al. Biomass-burning emissions and associated haze layers over Amazonia. I. Geophvs. Res. 1988, 93, 1509-1527.

(9) Pillar, E. A.; Camm, R. C.; Guzman, M. I. Catechol oxidation by ozone and hydroxyl radicals at the air-water interface. Environ. Sci. Technol. 2014, 48, 14352-14360.

(10) Pillar, E. A.; Zhou, R.; Guzman, M. I. Heterogeneous oxidation of catechol. I. Phvs. Chem. A 2015, 119, 10349-10359.

(11) Guenther, A.; Jiang, X.; Heald, C. L.; Sakulyanontvittaya, T.; Duhl, T.; Emmons, L. K.; Wang, X. The model of emissions of gases and aerosols from nature version 2.1 (MEGAN2. 1): an extended and updated framework for modeling biogenic emissions. Geosci. Model Dev. 2012, 5, 1471-1492.

(12) Rivera-Rios, J. C.; Nguyen, T. B.; Crounse, J. D.; Jud, W.; St. Clair, J. M.; Mikoviny, T.; Gilman, J. B.; Lerner, B. M.; Kaiser, J. B.; de 
Gouw, J.; et al. Conversion of hydroperoxides to carbonyls in field and laboratory instrumentation: Observational bias in diagnosing pristine versus anthropogenically controlled atmospheric chemistry. Geophvs. Res. Lett. 2014, 41, 8645-8651.

(13) Zimmermann, J.; Poppe, D. A supplement for the RADM2 chemical mechanism: The photooxidation of isoprene. Atmos. Environ. 1996, 30, 1255-1269.

(14) Fu, T. M.; Jacob, D. J.; Wittrock, F.; Burrows, J. P.; Vrekoussis, M.; Henze, D. K. Global budgets of atmospheric glyoxal and methylglyoxal, and implications for formation of secondary organic aerosols. I. Geophvs. Res. 2008, 113, D15303.

(15) Betterton, E. A.; Hoffmann, M. R. Henry's law constants of some environmentally important aldehydes. Environ. Sci. Technol. 1988, 22, 1415-1418.

(16) Wasa, T.; Musha, S. The polarographic behavior of glyoxal and its related compounds. Bull. Univ. Osaka Prefec. Ser. A 1970, 19, 169180.

(17) Carlton, A. G.; Turpin, B. J.; Lim, H. J.; Altieri, K. E.; Seitzinger, S. Link between isoprene and secondary organic aerosol (SOA): Pyruvic acid oxidation yields low volatility organic acids in clouds. Geophys. Res. Lett. 2006, 33, L06822.

(18) Lim, H.-J.; Carlton, A. G.; Turpin, B. J. Isoprene forms secondary organic aerosol through cloud processing: Model simulations. Environ. Sci. Technol. 2005, 39, 4441-4446.

(19) Epstein, S. A.; Tapavicza, E.; Furche, F.; Nizkorodov, S. A. Direct photolysis of carbonyl compounds dissolved in cloud and fog droplets. Atmos. Chem. Phys. 2013, 13, 9461-9477.

(20) Guzmán, M. I.; Hildebrandt, L.; Colussi, A. J.; Hoffmann, M. R. Cooperative hydration of pyruvic acid in ice. I. Am. Chem. Soc. 2006, $128,10621-10624$.

(21) Guzmán, M. I.; Hoffmann, M. R.; Colussi, A. J. Photolysis of pyruvic acid in ice: Possible relevance to $\mathrm{CO}$ and $\mathrm{CO}_{2}$ ice core record anomalies. L. Geophvs. Res. 2007, 112, D10123.

(22) Davidson, R. S.; Goodwin, D.; De Violet, P. F. The mechanism of the photo-induced decarboxylation of pyruvic acid in solution. Chem. Phvs. Lett. 1981, 78, 471-474.

(23) Guzman, M.; Colussi, A.; Hoffmann, M. Photogeneration of distant radical pairs in aqueous pyruvic acid glasses. I. Phys. Chem. A 2006, 110, 931-935.

(24) Davidson, R. S.; Goodwin, D. The role of electron transfer processes in the photoinduced decarboxylation reaction of $\alpha$-oxocarboxylic acids. I. Chem. Soc., Perkin Trans. 2 1982, 1559-1564.

(25) Davidson, R. S.; Goodwin, D.; Turnock, G. The direct photooxidative decarboxylation of $\alpha$-oxo-carboxylic acids. Tetrahedron Lett. 1980, 21, 4943-4946.

(26) Griffith, E. C.; Carpenter, B. K.; Shoemaker, R. K.; Vaida, V. Photochemistry of aqueous pyruvic acid. Proc. Natl. Acad. Sci. U. S. A 2013, 110, 11714-11719.

(27) Griffith, E. C.; Carpenter, B. K.; Shoemaker, R. K.; Vaida, V. Reply to Eugene et al.: Photochemistry of aqueous pyruvic acid. Proc. Natl. Acad. Sci. U. S. A. 2013, 110, E4276-E4276.

(28) Leermakers, P. A.; Vesley, G. F. The photochemistry of $\alpha$-keto acids and $\alpha$-keto esters. I. Photolysis of pyruvic acid and benzoylformic acid. I. Am. Chem. Soc. 1963, 85, 3776-3779.

(29) Eugene, A. J.; Xia, S.-S.; Guzman, M. I. Negative production of acetoin in the photochemistry of aqueous pyruvic acid. Proc. Natl. Acad. Sci. U. S. A. 2013, 110, E4274-E4275.

(30) Ronkainen, P.; Brummer, S.; Suomalainen, H. Determination of 2-acetolactic acid and 2-aceto-2-hydroxybutyric acid in a fermented solution by gas chromatography. Anal. Biochem. 1970, 34, 101-111.

(31) Kawamura, K.; Yasui, O. Diurnal changes in the distribution of dicarboxylic acids, ketocarboxylic acids and dicarbonyls in the urban Tokyo atmosphere. Atmos. Environ. 2005, 39, 1945-1960.

(32) Ho, K. F.; Cao, J. J.; Lee, S. C.; Kawamura, K.; Zhang, R. J.; Chow, J. C.; Watson, J. G. Dicarboxylic acids, ketocarboxylic acids, and dicarbonyls in the urban atmosphere of China. I. Geophvs. Res. 2007, 112 , D22S27.

(33) Andreae, M. O.; Schmid, O.; Yang, H.; Chand, D.; Yu, J. Z.; Zeng, L.-M.; Zhang, Y.-H. Optical properties and chemical composition of the atmospheric aerosol in urban Guangzhou, China. Atmos. Environ. 2008, 42, 6335-6350.

(34) Hartmann, D. L. Global Physical Climatology; Academic Press: San Diego, CA, 1994.

(35) Saxena, P.; Hildemann, L. M. Water absorption by organics: Survey of laboratory evidence and evaluation of UNIFAC for estimating water activity. Environ. Sci. Technol. 1997, 31, 3318-3324.

(36) Kreidenweis, S. M.; Petters, M. D.; DeMott, P. J. Singleparameter estimates of aerosol water content. Environ. Res. Lett. 2008, 3, 035002 .

(37) Physical Constants of Organic Compunds. In CRC Handbook of Chemistry and Physics, 97th ed.; Haynes, W. M., Ed.; CRC Press/ Taylor \& Francis: Boca Raton, FL, Internet Version 2017.

(38) Glasoe, P. K.; Long, F. A. Use of glass electrodes to measure

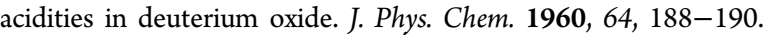

(39) Görner, H.; Kuhn, H. J. Photodecarboxylation of phenylglyoxylic acid: Influence of para-substituents on the triplet state properties. J. Chem. Soc., Perkin Trans. 2 1999, 2671-2680.

(40) Zhou, R.; Guzman, M. I. $\mathrm{CO}_{2}$ reduction under periodic illumination of ZnS. I. Phvs. Chem. C 2014, 118, 11649-11656.

(41) Webster, G.; Kumar, S. Expanding the analytical toolbox: Pharmaceutical application of quantitative NMR (q-NMR). Anal. Chem. 2014, 86, 11474-11480.

(42) Harris, D. C. Quantitative Chemical Analysis, 9th ed.; Freeman: New York, 2016.

(43) MestReNova; 6.1.0-6.2.24 ed.; Mestrelab Research S. L., 2010.

(44) Pavia, D.; Lampman, G.; Kriz, G. Introduction to spectroscopy, 3rd ed.; Thomson Learning, Inc., 2001.

(45) Anslyn, E. V.; Dougherty, D. A. Modern Physical Organic Chemistry; University Science Books: Sausalito, CA, 2006.

(46) Yamamoto, S.; Back, R. A. The photolysis and thermal decomposition of pyruvic acid in the gas phase. Can. I. Chem. 1985, 63, 549-554.

(47) Propper, R.; Wong, P.; Bui, S.; Austin, J.; Vance, W.; Alvarado, Á.; Croes, B.; Luo, D. Ambient and emission trends of toxic air contaminants in California. Environ. Sci. Technol. 2015, 49, 1132911339 .

(48) Gilbert, N. L.; Guay, M.; Miller, J. D.; Judek, S.; Chan, C. C.; Dales, R. E. Levels and determinants of formaldehyde, acetaldehyde, and acrolein in residential indoor air in Prince Edward Island, Canada. Environ. Res. 2005, 99, 11-17.

(49) Schuchmann, M. N.; Von Sonntag, C. The rapid hydration of the acetyl radical. A pulse radiolysis study of acetaldehyde in aqueous solution. I. Am. Chem. Soc. 1988, 110, 5698-5701.

(50) von Sonntag, C.; Schuchmann, H. P. The elucidation of peroxyl radical reactions in aqueous solution with the help of radiationchemical methods. Angew. Chem. Int. Ed. Engl. 1991, 30, 1229-1253.

(51) Neta, P.; Huie, R. E.; Ross, A. B. Rate constants for reactions of peroxyl radicals in fluid solutions. I. Phys. Chem. Ref. Data 1990, 19, 413-513.

(52) Herrmann, H.; Schaefer, T.; Tilgner, A.; Styler, S. A.; Weller, C.; Teich, M.; Otto, T. Tropospheric aqueous-phase chemistry: Kinetics, mechanisms, and its coupling to a changing gas phase. Chem. Rev 2015, 115, 4259-4334.

(53) Baxendale, J. H.; Wilson, J. A. The photolysis of hydrogen peroxide at high light intensities. Trans. Faradav Soc. 1957, 53, 344356.

(54) McNeill, V. F. Aqueous organic chemistry in the atmosphere: Sources and chemical processing of organic aerosols. Environ. Sci. Technol. 2015, 49, 1237-1244.

(55) Finlayson-Pitts, B. J.; Pitts, J. Chemistry of the Upper and Lower Atmosphere; Academic Press: San Diego, CA, 1999.

(56) Schöne, L.; Herrmann, H. Kinetic measurements of the reactivity of hydrogen peroxide and ozone towards small atmospherically relevant aldehydes, ketones and organic acids in aqueous solutions. Atmos. Chem. Phys. 2014, 14, 4503-4514.

(57) Schaefer, T.; Schindelka, J.; Hoffmann, D.; Herrmann, H. Laboratory kinetic and mechanistic studies on the $\mathrm{OH}$-initiated 
oxidation of acetone in aqueous solution. I. Phvs. Chem. A 2012, 116, 6317-6326.

(58) Horowitz, A.; Meller, R; Moortgat, G. K. The UV-VIS absorption cross sections of the $\alpha$-dicarbonyl compounds: pyruvic acid, biacetyl and glyoxal. I. Photochem. Photobiol. A 2001, 146, 19-27.

(59) Mellouki, A.; Mu, Y. On the atmospheric degradation of pyruvic acid in the gas phase. I. Photochem. Photobiol., A 2003, 157, 295-300. 